\title{
Neural Correlates of Competing Fear Behaviors Evoked by an Innately Aversive Stimulus
}

\author{
Raymond Mongeau, ${ }^{1}$ Gabriel A. Miller, ${ }^{1}$ Elizabeth Chiang, ${ }^{1}$ and David J. Anderson ${ }^{1,2}$ \\ ${ }^{1}$ Division of Biology and ${ }^{2}$ Howard Hughes Medical Institute, California Institute of Technology, Pasadena, California 91125
}

Environment and experience influence defensive behaviors, but the neural circuits mediating such effects are not well understood. We describe a new experimental model in which either flight or freezing reactions can be elicited from mice by innately aversive ultrasound. Flight and freezing are negatively correlated, suggesting a competition between fear motor systems. An unfamiliar environment or a previous aversive event, moreover, can alter the balance between these behaviors. To identify potential circuits controlling this competition, global activity patterns in the whole brain were surveyed in an unbiased manner by c-fos in situ hybridization, using novel experimental and analytical methods. Mice predominantly displaying freezing behavior had preferential neural activity in the lateral septum ventral and several medial and periventricular hypothalamic nuclei, whereas mice predominantly displaying flight had more activity in cortical, amygdalar, and striatal motor areas, the dorsolateral posterior zone of the hypothalamus, and the vertical limb of the diagonal band. These complementary patterns of $c$-fos induction, taken together with known connections between these structures, suggest ways in which the brain may mediate the balance between these opponent defensive behaviors.

Key words: defense behaviors; ultrasound; C56Bl6 mice; anxiety; flight behavior; freezing behavior; septum; hypothalamus; pedunculopontine tegmentum; diagonal band; cingulate cortex; motor cortex; retrosplenial cortex; accumbens; caudate putamen; amygdala

\section{Introduction}

Studies of defensive behaviors in rodents provide useful paradigms to understand how the environment influences the type of motor response evoked by aversive or fearful stimuli. In rodents, flight behaviors are predominantly observed in situations in which a threat is proximal or when escape routes are available, whereas freezing most often occurs when a threat is distal or inescapable (Blanchard et al., 1989, 2001). Most previous work on the neural circuitry of fear has focused on learned (conditioned) fear (LeDoux, 1995; Maren and Fanselow, 1996). Such work has the advantage that fear reactions can be elicited by a well defined unimodal stimulus, such as an auditory cue. Therefore, comparisons of brain activity evoked by the same stimulus before and after conditioning are possible. However, the predominant behavioral response to such conditioned stimuli is freezing. Both flight and freezing behaviors can be elicited from rodents exposed to a natural predator. However, these models usually involve complex, polymodal stimuli that are difficult to standardize or to quantify because of variable experimental conditions and animal handling (Canteras et al., 1997; Dielenberg et al., 2001). Therefore, there have been relatively few brain-imaging studies with innate fear stimuli.

Here we present a new experimental model in which freezing or flight behaviors or both can be consistently evoked from inbred mice on first presentation by an innately aversive, well defined auditory stimulus. The balance between these two behav-

\footnotetext{
Received Dec. 2, 2002; revised Feb. 14, 2003; accepted Feb. 19, 2003

This work was supported in part by a Keck foundation grant to California Institute of Technology. D.J.A. is an investigator of the Howard Hughes Medical Institute. We thank Gabriele Mosconi and Jennifer Uyeda for technical assistance and Erin Schuman, Nirao Shah, and Eric Kandel for comments on this manuscript.

Correspondence should be addressed to David J. Anderson, Howard Hughes Medical Institute, 216-76 California Institute of Technology, Pasadena, CA 91125. E-mail: wuwei@caltech.edu.

Copyright $\odot 2003$ Society for Neuroscience $\quad$ 0270-6474/03/233855-14\$15.00/0
}

iors can, moreover, be altered in a predictable manner by simple environmental manipulations. Naive mice exposed to an ultrasonic stimulus in their home cage predominantly display flight and freeze very little. By contrast, mice placed in an unfamiliar environment or treated with foot shocks the previous day primarily display freezing and less flight. We find that occurrences of flight and freezing, which can in principle both be exhibited by an individual animal during different intervals of the same testing period, are negatively correlated. This observation suggests the existence of competing motor systems underlying these alternative defensive motor responses.

To elucidate neural correlates of this behavioral switch, we have used c-fos mRNA expression to provide a global map of neural activity, with single-cell resolution, in the brains of naive and shock-sensitized animals responding to the aversive ultrasonic stimulus. Two important features have been incorporated to facilitate the interpretation of the c-fos mapping data. First, the aversive stimulus was delivered in animals' home cages, to avoid the influence of animal handling on c-fos expression patterns. Second, the stimulus was of a single sensory modality, to permit precise control over stimulus parameters. In this way, the observed neural activity patterns predominantly reflect stimulusresponse relationships, rather than stress or novelty imposed by the testing environment.

We have also developed a novel analytic approach to measure the density of $\mathrm{c}-\mathrm{fos}^{+}$cells in relevant regions across the entire brain. Cells expressing c-fos mRNA are revealed by nonisotopic in situ hybridization on thick $(120 \mu \mathrm{m})$ floating sections, permitting analysis of virtually the entire brain with a manageable number of sections. Two methods have been developed to analyze these data. A computerized macroanalysis technique is first used to scan the whole brain to detect potential areas of differential c-fos activity between animals under the two conditions. Subse- 
quently, the densities of $\mathrm{c}-\mathrm{fos}^{+}$cells in these regions are rigorously quantified using design-based stereology, a method that avoids common histological biases (Mayhew and Gundersen, 1996; Howard and Rose, 1998; Geuna, 2000). This approach has allowed the analysis of $>70$ different brain structures and identified among them different regions that show preferential c-fos mRNA expression under conditions of either flight or freezing. These results have been used, in conjunction with known connectional and functional data relevant to these regions, to construct a heuristic circuit that may control the switch between competing motile and immobile defensive behaviors.

\section{Materials and Methods}

Male C57Bl6/N mice from Harlan Sprague Dawley (San Diego, CA), aged between 6 and 12 weeks, were individually housed and maintained on a $12 \mathrm{hr}$ light/dark cycle with ad libitum access to food and water. All mice were single-housed 2-4 d before any experimental procedure. On the first day, two groups of mice were sensitized using 30 foot shocks $(0.5$ $\mathrm{mA}, 6 \mathrm{sec}$, with an average of $1 \mathrm{~min}$ intertrial intervals) and were subsequently placed back into their home cages. The behavioral apparatus (Coulbourn) used for the sensitization session consisted of four identical chambers $\left(175 \mathrm{~cm}^{3}\right)$ situated in a cabinet located in a dimly lit and isolated room. Foot shocks were delivered through rods wired to a shock generator and a scrambler. The second day, all groups were tested for their innate fear reactions to a train of ultrasonic stimuli $(100 \mathrm{msec}$ frequency sweeps between 17 and $20 \mathrm{kHz}, 85 \mathrm{~dB}$, alternately $\mathrm{ON} 2 \mathrm{sec}$ and then OFF 2 sec for $1 \mathrm{~min}$ after a $3 \mathrm{~min}$ baseline period). Flight behavior triggered during the $\mathrm{ON}$ periods is defined as an event of running from one side of the cage to the other followed by behavioral arrest, whereas the freezing behavior sampled every $4 \mathrm{sec}$ during the OFF period is defined as complete immobility except for respiration. Cages ( $165 \mathrm{~cm}$ wide, $275 \mathrm{~cm}$ long, and $155 \mathrm{~cm}$ high) were placed into a Plexiglas container, with a speaker (Optimus Bullet horn tweeter; Tandy) attached to a lid, providing additional sound insulation, inside an isolated room different from the one in which the foot shocks were delivered. The ultrasonic stimulus was produced using a function generator (Telulex SG-100/A). A portable sound pressure meter was calibrated using a microphone sensitive to $20 \mathrm{kHz}$ ultrasound and a computer-based spectrograph.

For the feeding suppression test of anxiety, different groups of mice were single-housed, and foot shock sensitization was done as described above. All mice were deprived of their regular food $24 \mathrm{hr}$ before the test and then brought to the standard testing environment, except that they were not exposed to any acoustic stimulus. The latency to feed was measured with a video camera from the time the pellets were placed in the center of the cage until the animal began to feed.

For c-fos analysis, naive and shock-sensitized mice were killed $30 \mathrm{~min}$ after delivery of the ultrasonic stimulus in their home cages. For baseline c-fos expression analysis, we killed naive and sensitized mice taken directly from their home cages without ultrasound exposure. Their brains were collected, cut in 3-4 mm coronal slabs using a block, and fixed overnight in 4\% paraformaldehyde. In brief, free-floating-section in situ hybridization was performed as follows: First, $120-\mu \mathrm{m}$-thick coronal sections were made from the tissue slabs using a vibratome. Then the sections were gently digested for $30 \mathrm{~min}$ using proteinase $\mathrm{K}$, fixed with $4 \%$ paraformaldehyde, and hybridized at $60^{\circ} \mathrm{C}$ overnight with a cRNA digoxygenin-labeled probe specifically binding c-fos mRNA. The nonhybridized probe was washed off at $60^{\circ} \mathrm{C}$ and digested with RNase $A$ at $37^{\circ} \mathrm{C}$ for $30 \mathrm{~min}$. Immunohistochemistry was performed using antidigoxygenin conjugated with alkaline phosphatase (Roche Molecular Biochemicals, Indianapolis, IN). Development was performed with an alkaline phosphatase substrate generating a blue product, and the sections were counterstained with nuclear fast red (Vector Laboratories, Burlingame, CA). Preliminary tests confirmed that all the reagents adequately penetrated the $120-\mu \mathrm{m}$-thick sections.

For the macroanalysis process, whole-section mosaics of highmagnification photomicrographs were assembled using a computerized stage and a CCD camera using Neurolucida software. Cell profiles from the most densely stained cells were then thresholded (on the blue chan- nel) and transformed into vectors (yellow markers) to provide a preliminary population estimate for stereological measurements and to identify regions with possible changes between groups. The images from three sections were overlaid to make $360 \mu \mathrm{m}$ virtual sections and to better view the cell distribution in regions of low cell density. These virtual sections were not necessary in cases in which the cell distribution was already obvious from a microphotograph.

For stereology, the outlines of local brain areas to be counted, derived from a standard mouse brain atlas (Paxinos and Franklin, 2001), were digitally fitted at low magnification $(4 \times)$ on the original specimens and manually corrected for shrinkage and section distortion. Cell counts were performed at $40 \times$ magnification using the optical fractionator $(50 \times 50 \times 60 \mu \mathrm{m}$ counting bricks randomly sampled) automatically operated by the StereoInvestigator software. The identity of each brain area was confirmed using strict distance measurements from anatomical cues in all directions that were clearly visible by virtue of the nuclear fast red counterstaining on thick sections. Importantly, brain areas were never defined by the c-fos staining. Volumes were measured by planimetry, and coefficients of variation of the sampling distribution for cell density estimates were always $\leq 5 \%$ (Schaeffer's test). Three different animals were analyzed from each group (naive and sensitized), and Student's $t$ test was used to evaluate the statistical differences in between groups. Detailed information about the in situ hybridization procedure, the stereological quantification, and the macroanalysis processes can be found in on-line Appendix A (available at www.jneurosci.org).

\section{Results}

\section{Identification of innately aversive unimodal stimuli in mice}

We initially undertook identification of unimodal sensory stimuli that could reliably elicit robust defensive behaviors in inbred strains of laboratory mice on first presentation. Predator odors produced risk assessment behaviors such as stretch-attend and inhibition of grooming, but intense fear reactions such as flight or freezing were not observed in $\mathrm{C} 57 \mathrm{Bl} / \mathrm{N}$ mice. Moreover, the intensity and duration of these olfactory stimuli were difficult to control and to normalize to neutral control stimuli. Subsequently, we experimented with ultrasonic tones in the $\sim 20 \mathrm{kHz}$ range, because rats are known to emit alarm vocalizations in this range and to respond to such auditory stimuli with defensive behaviors (Blanchard et al., 1992; Cuomo et al., 1992; Beckett et al., 1996).

Preliminary studies indicated that explosive defensive responses could be reliably elicited in $\mathrm{C} 57 \mathrm{Bl} / \mathrm{N}$ mice using a continuous $20 \mathrm{kHz}$ square-pulse signal, and that this stimulus was more effective than a sine-wave signal. Nevertheless, we chose to use sine-wave signals, because ordinary sound pressure meters cannot detect the contribution to overall decibel levels of the harmonics generated by square-pulse signals. We found that patterning the ultrasonic stimulus, by introducing fast frequency sweeps between 17 and $20 \mathrm{kHz}$, was more effective in producing fear reactions than were continuous tones at any given frequency within this range. Our optimized stimulus consisted of a train of $100 \mathrm{msec} 17-20 \mathrm{kHz}$ frequency sweeps delivered at $85 \mathrm{~dB}$, alternately $\mathrm{ON}$ for $2 \mathrm{sec}$ and then OFF for $2 \mathrm{sec}$, for $1 \mathrm{~min}$.

The most frequent reactions elicited by this ultrasound from naive mice in their home cages were flight (which is defined as an event of running from one side of the cage to the other, followed by arrest), rapid breathing, and swift circular defense behaviors. Occasionally we also observed tail rattling and jumping. Importantly, none of these behaviors occurred during baseline observations. In contrast, behaviors such as grooming and rearing, which frequently occurred during baseline, were markedly decreased during presentation of the stimulus. In addition to these changes in motor behavior, the ultrasonic stimulus elicited a rise in serum corticosterone and heart rate (measured by radioim- 
A

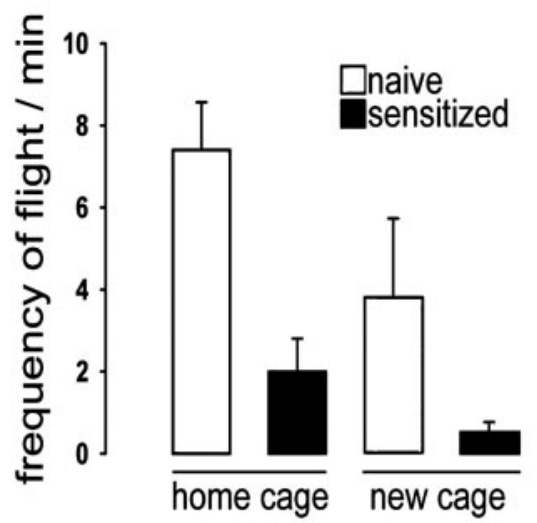

B

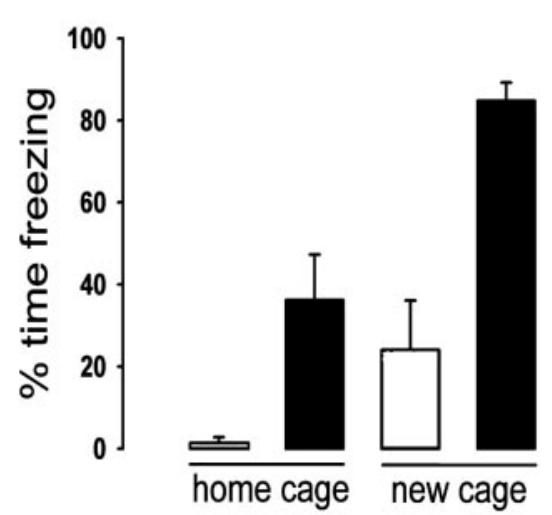

C

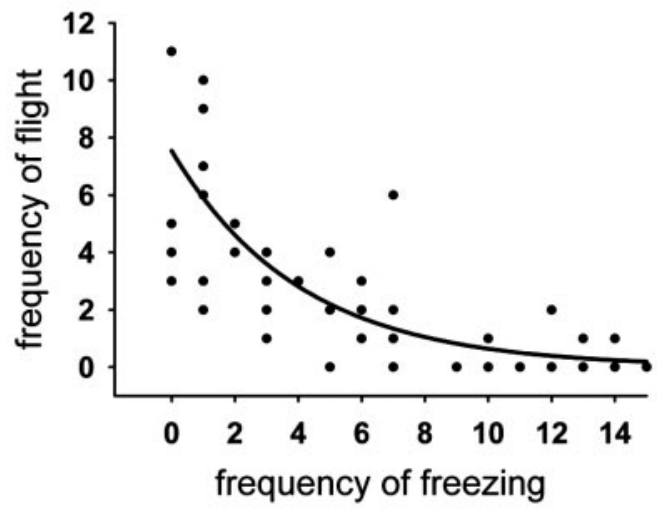

Figure 1. Modulation of defense reactions to an innately aversive ultrasound (USS). The frequency of flight $(A)$ and freezing $(B)$ is compared for $\mathrm{N}$ (white bars) and $S$ (black bars) mice. $A, S$ mice showed significantly less flight than N mice (ANOVA, $p<0.01$ ), as did mice exposed to the USS in a new cage $(p<0.05)$. $B, S$ mice showed significantly more freezing than $N$ mice in their home cages $(p<0.01)$, as did mice in a new cage $(p=0.01)$. Data represent mean $\pm S E M ; n=5-7$ mice. C, Correlation analysis with all parameters combined revealed a significant (AN0VA, $p<0.001$; $\left.r^{2}=0.6\right)$ negative correlation between the frequency of flight and freezing. Each point represents a single animal $(n=38)$. The coefficient of variation of the slope was $9 \%$.

muno assay and telemetry; data not shown). These behavioral, endocrine, and autonomic responses support the inference that the ultrasonic stimulus elicits strong and reliable fear reactions in laboratory mice.

\section{Anxiogenic manipulations cause changes in ultrasound- evoked defense behaviors}

When mice in their home cage were exposed to the ultrasonic stimulus, frequent flight responses (six to eight events/min) were observed during the ON periods (Fig. $1 A$, home cage, white bar), but there were very few bouts of freezing (measured during the OFF periods as complete immobility except for respiration; Fig. $1 B)$. By contrast, when animals were exposed to the ultrasound in an unfamiliar cage, the frequency of flight events was reduced to approximately half that of home cage mice (Fig. $1 A$, new cage, white bar), and significantly more episodes of freezing were observed (Fig. $1 B$, new cage, white bar, compare home cage). A similar reduction of flight and an increase in freezing were observed in animals tested in their home cage after being exposed 24 hr earlier to a series of foot shocks ( 30 shocks of $0.5 \mathrm{~mA}$ for $6 \mathrm{sec}$ each; Fig. $1 A, B$, home cage, black bar, compare white bars). When the foot-shocked animals were tested in a new cage, flight responses were almost completely suppressed, and freezing was maximal (Fig. 1 $A, B$, new cage, black bars). Freezing events were seldom observed $(6.7 \pm 3.4 \%$ of the time $)$ in shock-sensitized mice during exposure to a neutral auditory tone $(2 \mathrm{kHz}$ sine wave, $1 \mathrm{~min}, 85 \mathrm{~dB}$ ) compared with a group of mice exposed to the aversive ultrasound at the same sound pressure $(54.6 \pm 10.6 \%$ of the time).

Flight was triggered primarily during the stimulus ON period, whereas freezing occurred during the OFF period. Therefore, we measured flight responses during the $\mathrm{ON}$ period and freezing responses during the OFF period. Hence, we could theoretically measure maximal flight and freezing responses from an individual animal during a given experiment. Nevertheless, when the frequency of flight and freezing to the stimulus for individual mice $(n=38)$ was plotted for all animals tested (collapsing both sensitization and new cage factors), a significant negative correlation between the two behaviors was observed (Fig. 1C; $p<$ $\left.0.001 ; r^{2}=0.6\right)$. This strong negative correlation is not simply a trivial consequence of the fact that flight and freezing are physically mutually exclusive. Bouts of freezing occupied limited intervals during the testing session (they rarely occurred during the ON period). Therefore, there was ample time for animals that froze to also display flight behavior. Conversely, episodes of flight are typically interrupted by pauses (during the stimulus OFF period) during which the animal can freeze. Indeed, many individual animals displayed episodes of both flight and freezing during the same testing period (Fig. $1 C$ ). The fact that flight occurrences nevertheless became much less frequent as the frequency of freezing increased therefore suggests that these behaviors are in competition with one another for reasons other than simple motor incompatibility.

One explanation for the effect of a novel environment, previous foot shock sensitization, or both on the balance between flight and freezing responses is that these two manipulations increase anxiety. To test this, we used an animal model of anxiety called the feeding suppression task (Bodnoff et al., 1988; Gross et al., 2000). In this paradigm, mice are presented with food in a given environment $24 \mathrm{hr}$ after being food-deprived. In both rats and mice, the latency to feed in this environment is greater with increasing anxiety-like states. Consistent with the idea that the novel environment increased anxiety, food-deprived mice transferred to a new cage had a significantly greater latency to feed compared with home cage controls (home cage, $110 \pm 19 \mathrm{sec}$; new cage, $189 \pm 18 \mathrm{sec} ; n=8 ; p=0.01$, Student's $t$ test). Combining the new cage and sensitization factors had an even larger effect, because foot-shocked mice placed in a new cage $24 \mathrm{hr}$ later had a greater latency to feed compared with naive animals in the new cage (naive, $173 \pm 20 \mathrm{sec}$; sensitized, $230 \pm 14 \mathrm{sec} ; n=6$ or $7 ; p<0.05)$. These data indicate that there is a correlation between manipulations that decrease flight and increase freezing and those that increase anxiety as determined by an independent behavioral test. Consistent with this interpretation, earlier studies have shown that shock sensitization increases anxiety in other behavioral tests, such as the elevated plus maze (Steenbergen et al., 1990).

We have also assessed ultrasound-induced defense after longterm treatment with the anxiolytic drug alprazolam (1 $\mathrm{mg} \cdot \mathrm{kg}^{-1} \cdot \mathrm{d}^{-1}$, i.p., for $10 \mathrm{~d}$, dissolved in $0.9 \%$ saline with a few 
drops of Tween 80 , and tested in the home cage $1 \mathrm{hr}$ after the last injection). After a control intraperitoneal saline injection (which is a stressful manipulation like shock sensitization or placement in a new cage), mice typically display some freezing and little flight in reaction to the aversive ultrasound. However, freezing was significantly reduced in mice injected with alprazolam compared with controls (saline, $25.7 \pm 6.8 \%$ of the time spent freezing; vs alprazolam, $6.7 \pm 4.2 \%$ of the time; $p<0.05 ; n=6$ ). In contrast, the frequency of flight tended to change in the opposite direction (saline, $2.8 \pm 1.1$ flight events; vs alprazolam, $6.8 \pm 2$ events; $p=0.11 ; n=6$ ). These data indicate that reducing anxiety increases ultrasonic stimulus (USS)-induced flight but decreases freezing, supporting the idea that anxiety conversely increases freezing and decreases flight.

\section{Functional imaging using quantitative analysis of c-fos mRNA-expressing cells}

We next sought to map global patterns of neuronal activity in the brains of naive $(\mathrm{N})$ and sensitized $(\mathrm{S})$ mice after their first exposure to the ultrasonic stimulus. To do this, we used a nonisotopic in situ hybridization method with single-cell resolution to examine expression of c-fos mRNA, the best characterized marker of neuronal metabolic activity (Herdegen and Leah, 1998). We chose to examine c-fos mRNA rather than protein because it is a more proximate indicator of c-fos expression. Induction of c-fos transcription in neurons occurs within $2-5 \mathrm{~min}$ in response to depolarization-induced calcium entry (Finkbeiner and Greenberg, 1998) and peaks after $\sim 30 \mathrm{~min}$ (Greenberg and Ziff, 1984), the time at which ultrasound-exposed animals were killed for analysis. c-fos expression can also be induced by factors that elevate intracellular cAMP expression, such as monoamines or neuropeptides, as well as by stress hormones [glucocorticoids (for review, see Herdegen and Leah, 1998)]. However, glucocorticoids are not the principal influences on c-fos expression in tasks involving stress (Anokhin et al., 1991; Helmreich et al., 1996).

Exposure of mice to the ultrasonic stimulus in their home cages was a key feature of our paradigm, because the handling of animals necessary to transfer them to a new testing cage induces a substantial number of $\mathrm{c}^{-} \mathrm{fos}^{+}$cells. By testing animals in their home cage, background levels of c-fos mRNA expression in control animals were kept very low (Fig. 2A). A reflection of the specificity of c-fos mRNA induction under these conditions is seen in the inferior colliculus (IC), which contains a tonotopic map of frequency-responsive neurons (Ryan et al., 1988; Ehret and Fischer, 1991). Exposure to the ultrasonic stimulus induced massive c-fos mRNA expression in a zone of the IC corresponding to the region sensitive to frequencies in the $17-20 \mathrm{kHz}$ range (Fig. $2 B$, arrow). That the expression of c-fos reflects motor output as well as sensory input is illustrated by its expression in the forelimb region of the motor cortex (Li and Waters, 1991), where there was a higher level of expression in $\mathrm{N}$ mice (which primarily exhibit flight) than in S mice (which primarily exhibit freezing; Fig. 2C; for quantification, see below). As expected (Castro-Alamancos et al., 1992), there was relatively little c-fos expression in regions of motor cortex not involved in the escape response (see supplemental Figure S7A, nose region; supplemental Figures S1-S8 can be found in on-line Appendix B).

To accurately quantify the induction of c-fos mRNA, we measured the density of $\mathrm{c}-\mathrm{fos}^{+}$cells in various brain regions using unbiased stereology with the optical fractionator. This method is considered the most accurate way to estimate cell densities in a given volume of brain tissue using a random sampling method. Surprisingly, however, it had not previously been used to map c-fos expression for functional imaging studies. By performing nonisotopic in situ hybridization on free-floating thick $(120 \mu \mathrm{m})$ sections, we could obtain a large "counting brick" (60 $\mu \mathrm{m}$ depth) with sufficient cellular resolution to estimate cell densities by optical dissection (Fig. 2G). To control for any differential shrinkage between sections, the volumes of brain regions sampled were calculated from section thickness and area measurements using well defined anatomical landmarks. For example, in the forelimb motor cortex we digitally fitted the anatomical boundaries [M1 and M2, located between anteroposterior (AP) -0.5 and $-1.9 \mathrm{~mm}$ ] from a digital brain atlas (Paxinos and Franklin, 2001) using landmarks such as the interhemispheric fissure and the corpus callosum. The measured volume for this entire region did not differ between groups $\left(\mathrm{N}, 0.94 \pm 0.06 \mathrm{~mm}^{3}\right.$; $\mathrm{S}, 0.95 \pm 0.03 \mathrm{~mm}^{3}$; in no case did we observe significant differences in volumes between groups for the regions sampled; therefore, the volumes are presented as a single value derived from both groups), but the density of $\mathrm{c}-\mathrm{fos}^{+}$cells was found to be higher in $\mathrm{N}$ than in $\mathrm{S}$ mice (Fig. $2 E$ ), consistent with the higher level of motor activity in the former group.

Because it was impractical to perform stereological cell counts through all brain regions in each of the three animals analyzed for each condition, we developed a method, called macroanalysis, to initially survey large regions of the brain to identify potential areas of differential c-fos expression and to obtain preliminary estimates of cell density. Briefly, this method uses the Neurolucida software to assemble low-magnification views of entire coronal sections with single-cell resolution by assembling a mosaic or "virtual slice" from a series of contiguous high-magnification fields (Fig. 2D, top panels). The positions of the most strongly stained $\mathrm{c}-\mathrm{fos}^{+}$cells in each section are then extracted using a thresholding program that identifies cell profiles on the basis of their color, dimension, and shape (Fig. $2 D$, bottom panel). Data from three consecutive virtual slices $(360 \mu \mathrm{m})$ can then be overlaid to clearly reveal the cell profile distribution within a given region [such as the functional columns within the periaqueductal gray (PAG); Fig. 2 F]. Automated counting of cell profiles could be performed within coarsely bounded regions for an animal of each group. Regions showing potential differences were then further analyzed by stereological counting in more tightly bounded regions.

\section{Neural correlates of the switch between flight and freezing behaviors}

For c-fos analysis, three $\mathrm{N}$ animals and three animals sensitized by foot shock $24 \mathrm{hr}$ previously (S) were exposed to the ultrasonic stimulus in their home cages. The behavioral data for these animals confirmed our previous findings (home cage $\mathrm{N}$ mice: flight, $7.0 \pm 1.2$ events; freezing, $4.3 \pm 4.3 \%$ of the time; home-cage S mice: flight, $1.7 \pm 0.9$ events; freezing, $60 \pm 14 \%$ of the time). The frequencies of both flight and freezing were significantly different between the two groups ( $p<0.05$, Student's $t$ test). The brain of each of these animals was cut into three large slabs (rostral, intermediate, and caudal), and each of these slabs was in turn sectioned at $120 \mu \mathrm{m}$ using a vibratome for in situ hybridization.

Approximately 70 different areas or nuclei were examined. [Table 1 in on-line Appendix B (available at www.jneurosci.org) summarizes the intensity of staining observed in various regions of the brain in $\mathrm{N}$ and $\mathrm{S}$ mice exposed to the ultrasonic stimulus.] Exposure to the aversive ultrasound produced massive increases of c-fos ${ }^{+}$cells in cortical, amygdalar, septo-hippocampal, and diencephalic areas but less so in the basal ganglia and the brainstem. Approximately $80 \%$ of the regions examined did not show signs of 

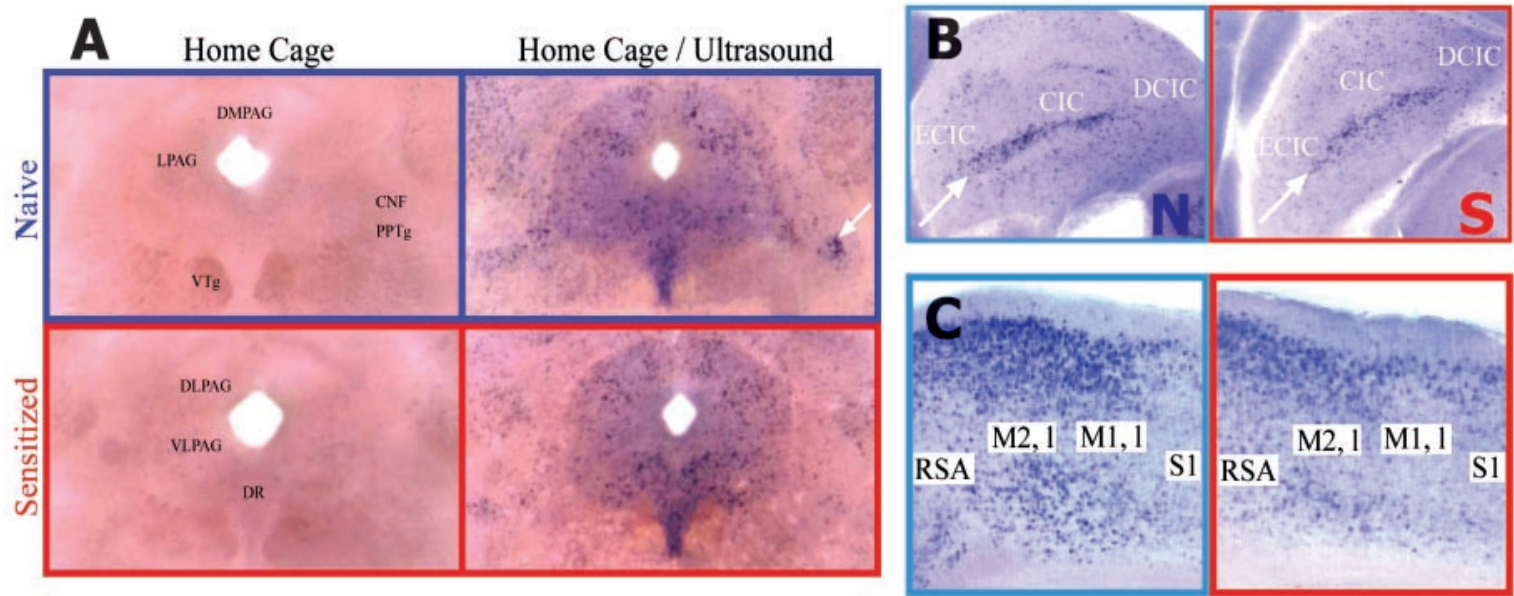

D

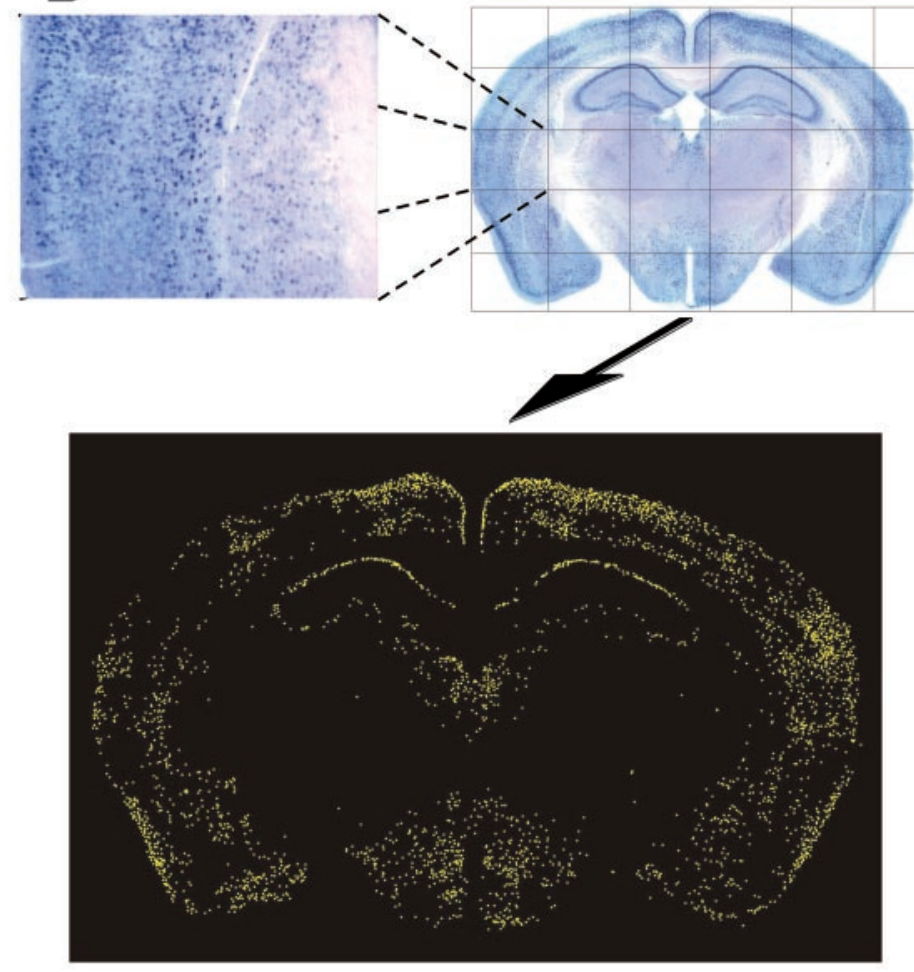

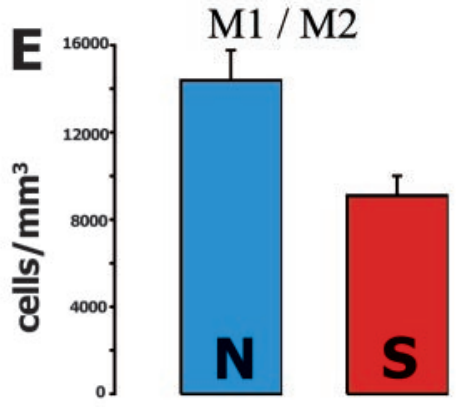

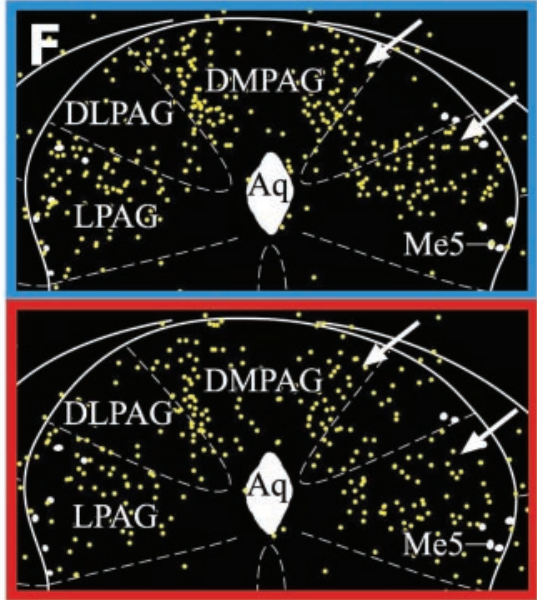

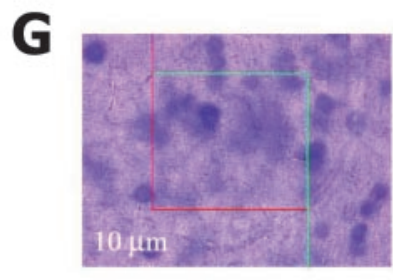
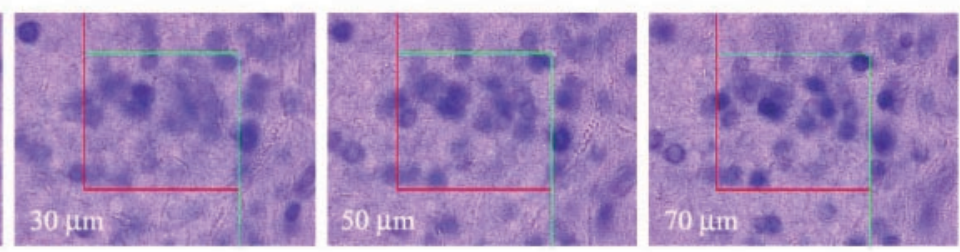

\section{Z-depth}

Figure2. Functional imaging using quantitative analysis of c-fos ${ }^{+}$cells. $A$, Background levels of c-fos $m R N A$ in $N$ (blue box) and $S$ (red box) mice. Control mice in their home cages had extremely low staining. The region illustrated is the PAG and is representative of other regions examined. The USS induced $c$-fos ${ }^{+}$cells in the dorsomedial and lateral periaqueductal gray (DMPAG, LPAG) and in the dorsal raphe (DR), as well as at the boundary of the cuneiform and the pedunculupontine nuclei (CnF, PPTg; white arrow). B, C, Photomicrographs in B indicate $c-$ fos ${ }^{+}$cells in the region of the inferior colliculus (IC; arrows) tonotopically appropriate to the USS, and those in ( show a higher density of $c$-fos ${ }^{+}$cells in the motor cortex of $\mathrm{N}$ mice exhibiting more flight than $S$ mice (see $E$ for quantification). D, Images illustrating the macroanalysis procedure. High-magnification photographs taken with a $6 \times$ objective are automatically assembled into a low-magnification mosaic of entire coronal sections using the Virtual Slice module of the Neurolucida program. This mosaic is then automatically transformed to a vector image representing the distribution of strongly stained cells (yellow dots). E, Stereological data (cells per cubic millimeter \pm SEM) showing the enhancement in motor cortical activity in Nversus Smice. Student's ttests indicated a significant $(p<0.05)$ increase in the hindlimb area of the motor cortex (M1,I,M2,I).F,Portions of overlaid macroanalysis images from three sections spanning $360 \mu \mathrm{m}$ were used to view the distribution of densely stained cell profiles in functional columns of the rostral portion of the DMPAG and LPAG (arrows). G, Photomicrographs $(40 \times)$ illustrating single-cell resolution of the c-fos mRNA in situ hybridization signals used for stereological measurements. For details, see Materials and Methods. 
differential activity. Approximately 14 regions were identified that showed higher levels of c-fos expression in $\mathrm{N}$ mice than in $\mathrm{S}$ mice, whereas only half as many showed higher activity in S mice (see Fig. 7). Strikingly, all but one of the latter regions are clustered in the hypothalamus. Approximately eight areas showed strong activity in both $\mathrm{N}$ and $\mathrm{S}$ mice. Below we systematically compare the detailed patterns of activity between $\mathrm{N}$ and $\mathrm{S}$ mice, beginning with the mesencephalon and ending with the cortex. Supplemental figures (S1-S8) can be found in on-line Appendix B (available at www.jneurosci.org).

\section{Mesencephalon}

The midbrain PAG is thought to serve as a final common pathway for the initiation of flight and freezing behaviors elicited by fearful stimuli (Bandler et al., 2000). Consistent with this, the PAG was strongly activated in mice exposed to the ultrasonic stimulus (Fig. $2 F$ ). However, there were no significant group differences in any region of this mesencephalic structure as assessed by stereological counting (Appendix B, Figs. S1, S6 A). There were also no apparent differences at the level of the inferior and superior colliculi (Figs. $2 B, \mathrm{~S} 3$ ), in the median and dorsal raphe nuclei (containing serotonin cell bodies (Figs. S2 A, S6A), and in the locus coeruleus (containing noradrenaline cell bodies (Fig. S2C), although staining was strong in these areas. There were very few $\mathrm{c}-\mathrm{fos}^{+}$cells in the ventral tegmental area or the substantia nigra (Fig. S2 B). The only area of the midbrain where we did observe a difference between $\mathrm{N}$ and $\mathrm{S}$ mice was at the lateral edges of the ventral PAG, at the junction between the pedunculopontine tegmentum (PPTg) and the cuneiform nucleus (Cnf) (Fig. 2A, arrow). Stereological cell counting in this area was performed within an arbitrarily defined octagonal region (Fig. S6 B), because this cluster of staining did not fit any known boundaries in the atlas. These measurements confirmed a significantly higher (55\%) density of c-fos cells within this defined boundary in N versus S mice (N, $2594 \pm 312$ cells $/ \mathrm{mm}^{3}$; S, $1795 \pm 23$ cells $/ \mathrm{mm}^{3} ; p<0.05$; between AP -4.4 and $-5.1 \mathrm{~mm}$; volume, $0.182 \pm 0.003 \mathrm{~mm}^{3}$ ).

\section{Diencephalon}

In contrast to the mesencephalon, the hypothalamus displayed numerous areas of differential activity that correlated with differences in either flight or freezing responses. In general, the lateral and posterior hypothalamus showed preferential activity in $\mathrm{N}$ mice, whereas many periventricular and medial hypothalamic nuclei showed preferential activity in S mice (Fig. 3). The hypothalamus has been subdivided into a series of four zones from rostral to caudal: the anterior, preoptic, tuberal, and mammillary zones. In the mammillary zone, the lateral portion of the posterior hypothalamus $(\mathrm{PH})$ was strongly activated in both groups but was somewhat higher (47\%) in $\mathrm{N}$ mice (Fig. $3 A$, arrow, $B$ ). In the tuberal zone, there was strong labeling in both groups in the dorsomedial hypothalamus and in the dorsomedial portion of the ventromedial hypothalamic nucleus (Fig. 3C), two areas implicated in defensive behaviors (Graeff, 1990; Canteras, 2002). By contrast, the ventrolateral portion of this nucleus, which has been implicated in reproductive behaviors, was weakly labeled (Fig. $3 C$, VMHVL). The lateral hypothalamus, also in the tuberal zone, had a significantly higher level of activity in $\mathrm{N}$ mice $(80 \% ; p<$ 0.05 ; Fig. $3 D$ ), mostly in the dorsal aspect that mediates aversion (Fig. S4A) (Cazala and Schmitt, 1987).

A number of other hypothalamic areas showed preferential activity, conversely, in S mice (Fig. $3 G-L$ ). In the anterior zone, the paraventricular nucleus $(\mathrm{Pa})$ showed an overall increase of $48 \%$ in S mice, but the difference was more apparent in the dorsal portion of the nucleus (Fig. 3E, arrow, $F$ ). There was no difference between $\mathrm{N}$ and $\mathrm{S}$ mice in the anterior hypothalamic nuclei, although it was activated in both cases (Fig. $3 E$ ). In the preoptic hypothalamic zone, there were two areas that showed strongly preferential c-fos expression in S mice: the medial preoptic nucleus (MPO) and the anterodorsal preoptic nucleus (ADP) (Fig. $3 G-J)$. In the ADP, there was a nearly threefold activity increase in $\mathrm{S}$ relative to $\mathrm{N}$ mice (Fig. $3 J$ ), whereas in the MPO, the level of activity was doubled (Fig. $3 H$ ). This latter result was somewhat surprising, because the MPO is usually considered to be part of the medial hypothalamic behavioral control column for reproductive behaviors (Pfaus et al., 1993). The c-fos ${ }^{+}$cells were particularly dense around the midline and also at the ventral junction with the medial preoptic area (Fig. 3G), but there was a relative gap in c-fos labeling in the more lateral domain of the MPO (Fig. 3G). In other studies, this domain has been shown to strongly express c-fos in animals performing reproductive behaviors (Pfaus et al., 1993). These observations suggest that the MPO may be subdivided into regions involved in defense and reproduction.

In the premammillary zone, there was strong but equivalent c-fos expression in both groups in the dorsal premammillary nucleus (Fig. $3 \mathrm{~K}$ ), a structure required for both freezing and flight responses to a predator (Canteras et al., 1997). In this same region, S mice displayed higher activity $(61 \%)$ in a domain at the junction of the premammillary ventral nucleus (PMv) and arcuate nucleus (Fig. $3 K$, arrow, $L$ ). The central region of the PMv, previously implicated in sexual behaviors (Yokosuka et al., 1999), had little staining. Finally, although we found a substantial amount of c-fos activity in other regions of the diencephalon, there were no apparent differences between $\mathrm{N}$ and $\mathrm{S}$ mice in any portion of the epithalamus, the subthalamus, or the thalamus (Fig. S4B).

\section{Septal and hippocampal areas}

The most striking difference between $\mathrm{S}$ and $\mathrm{N}$ mice was in the lateral septum ventral (LSV). As shown in Figure 4, there was a major increase $(+173 \%)$ in the density of positive cells in the LSV of S mice (Fig. $4 A, D$ ). In fact, the LSV was one of the few regions where a difference in c-fos expression between $\mathrm{N}$ and $\mathrm{S}$ mice was evident by visual inspection of the sections, without the need for macroanalysis. In the most caudal portion of the septum, the stained cells were highly clustered within the boundary of the LSV (Fig. 4A, arrows). At more rostral levels, $\mathrm{c}-\mathrm{fos}^{+}$cells in $\mathrm{S}$ mice clustered in the LSV along the edge of the lateral ventricle, and there was also a substantial amount of staining in the adjacent lateral septum intermediate (LSI). However, the density of positive cells in the LSI of S mice was not significantly different from that of $\mathrm{N}$ mice (Fig. $4 E$ ). There was relatively little activity, and no apparent difference between $\mathrm{N}$ and $\mathrm{S}$ mice, in the lateral septum dorsal. Cell density was generally low in the medial septum and the horizontal limb of the diagonal band. In sharp contrast to the LSV, the vertical limb of the diagonal band (VDB) showed a much higher $(136 \%)$ density of $\mathrm{c}-$ fos $^{+}$cells in $\mathrm{N}$ than in $\mathrm{S}$ mice (Fig. $4 B, C$ ). The positive cells appeared as a well defined cluster at the base of the septum (Fig. $4 B$ ).

The bed nucleus of the stria terminalis (BNST) is composed of multiple subnuclei, whose classification varies according to different authors (Alheid et al., 1995). The contours that were used for stereological measurements in this analysis did not follow those defined by Paxinos and Franklin (2001). We refer here to the anterior BNST (BNSTa) as all the subdivisions of the BNST within the region bounded caudally by the posterior part of the 

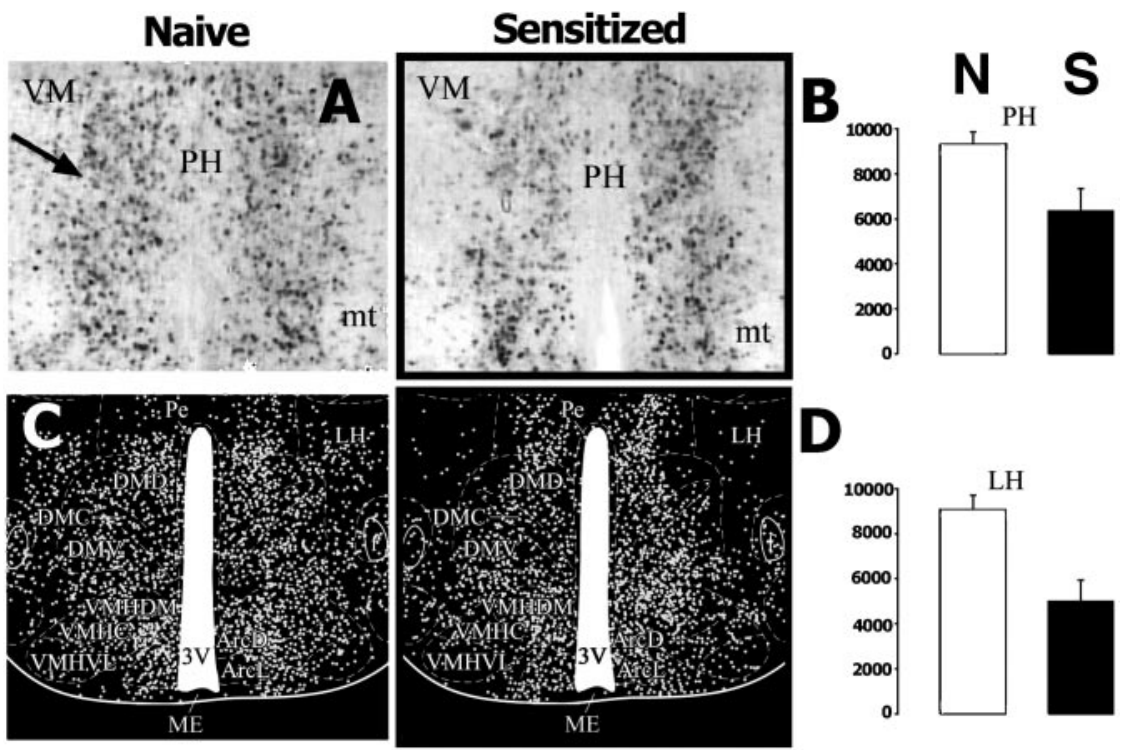

\section{D}
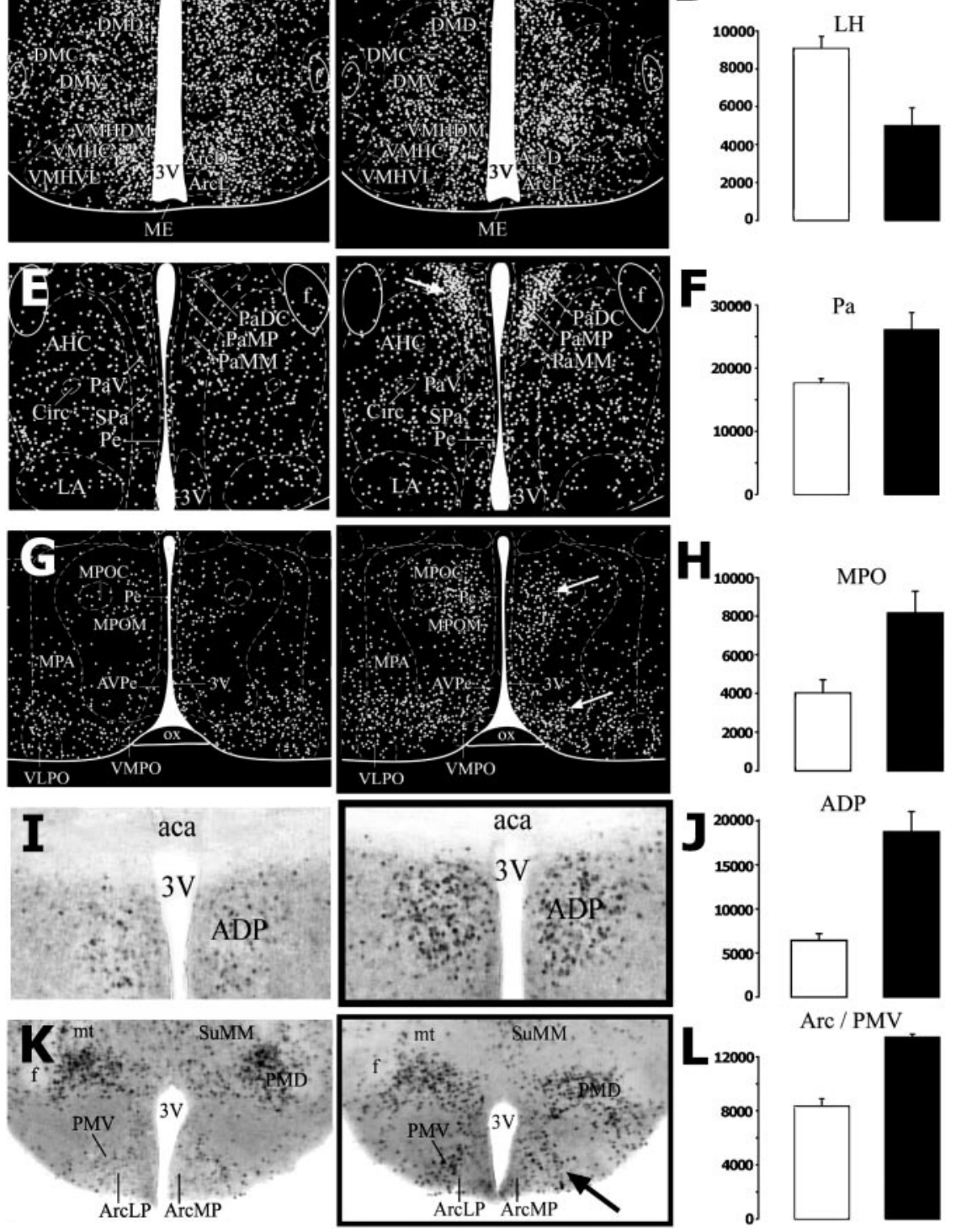

anterior commissure and rostrally by the shell of the nucleus accumbens. There was an increased density of c-fos ${ }^{+}$cells (73\%) in the BNSTa of N compared with S mice (Fig. 4F,I, arrows). In contrast, the bed nucleus of the commissural component of the stria terminalis (CST) (Alheid et al., 1995) did not reveal any group differences (Fig. $4 G, J)$. In other areas of the BNST, c- fos $^{+}$cell density was generally low, and there was no evidence of differential activity. In the dorsal hippocampus, there were high densities of c- $\mathrm{fos}^{+}$cells in CA1, moderate densities in CA2 and CA3, and a low density in the dentate gyrus (Fig. $4 H$ ) but no apparent group differences in any of these regions.

Amygdalar and striatal areas

In both $\mathrm{N}$ and $\mathrm{S}$ mice, positive cells in the lateral and basolateral amygdala tended to cluster in the most medial portion of these nuclei. There were no apparent group differences in these predominantly sensory regions of the amygdala (Fig. 5C). By contrast, in the basomedial amygdala, there was a greater than twofold increase in the density of positive cells in $\mathrm{N}$ mice, and the cells tended to cluster toward the corticomedial amygdala (Fig. 5A,B). A similar change in $\mathrm{N}$ mice $(+123 \%)$ was found in the medial amygdala anterior (Fig. 5E,F). In the most caudal sections, there was an apparent cluster of $\mathrm{c}-\mathrm{fos}^{+}$cells encompassing both the medial amygdala posterior ventral and the anterior cortical nucleus (Fig. 5D,K), whose density was approximately twofold higher in $\mathrm{N}$ mice (Fig. 5I). Although the central nucleus of the amygdala is known to be involved in the expression of conditioned freezing, there were no significant differences between $\mathrm{N}$ and $\mathrm{S}$ mice throughout the rostrocaudal extent of this structure (Fig. $5 A, L)$. Strikingly, in no case did we identify any amygdalar regions that showed more activity in $\mathrm{S}$ than in $\mathrm{N}$ mice.

Few areas of the basal ganglia had any staining. There were hardly any c-fos ${ }^{+}$ cells in any of the pallidal areas, whereas activity in the caudate putamen was restricted to areas innervated by the auditory cortex (McGeorge and Faull, 1989). These included the dorsomedial portion of the rostral caudate putamen $(\mathrm{CPu})$ and the posterior $\mathrm{CPu}$ (Fig. 5G,H). There are no boundaries in the mouse atlas corresponding to the dorsomedial CPu. Therefore, this region was arbitrarily defined by measuring a triangular area delimited by nodes $500 \mu \mathrm{m}$ perpendicular to the lateral ventricle and connected to the most ventral edge of the lateral ventricle. Mice disbetween $A P+0.3$ and $-0.3 \mathrm{~mm}$ (volume, $\left.0.037 \pm 0.002 \mathrm{~mm}^{3} ; p<0.01 ; J\right)$, and the PMv and Arc located between AP $-2.1 \mathrm{and}-2.7 \mathrm{~mm}$ (volume, $\left.0.045 \pm 0.003 \mathrm{~mm}^{3} ; p<0.01 ; L\right)$.

Figure 3. Data indicating changes in the density and the distribution ofc-fos ${ }^{+}$cells in thehypothalamus. In Nmice, staining was moreintensein bars, N mice; black bars, S mice) indicated a greater density of c-fos ${ }^{+}$cells in N versus $\mathrm{S}$ mice in the PH located between AP -1.8 and - $2.5 \mathrm{r}$ $0.05 ; D)$. Virtual sections and arrows show more intense staining in $S$ mice in the dorsal and magnocellular portions of the paraventricular nucleus $[\mathrm{PaD}, \mathrm{PaM}$; no changein the central orlateral portion of the anteriorhypothalamus $(\mathrm{AH}, \mathrm{LA}) ; \mathrm{E}]$ and in the medial and ventral portions of the $\mathrm{MPO}(G)$. I, K, Photomicrographs show a duster of cells in the ADP of S mice and its relative absence in N mice ( / ) and in cells more apparent at the boundary of the PMv and the arcuate nucleus (Arc) inSmice $(K)$. There was the same apparent number of cells in the dorsal PMd. Stereological counting (cellsper cubic millimeter \pm SEM) indicated a greater density of $c-$ fos ${ }^{+}$cells in S versus N mice in the Pa located between AP -0.5 and $-1.1 \mathrm{~mm}$ (volume, $0.059 \pm 0.001 \mathrm{~mm}^{3} ; p<0.05 ; F$ ), theMPO located between AP 0.0 and $-0.6 \mathrm{~mm}$ (volume, $0.235 \pm 0.002 \mathrm{~mm}^{3} ; p<0.05 ; H$ ), the ADP located 


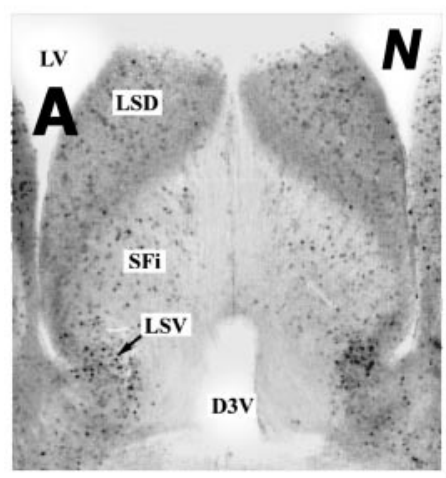

D

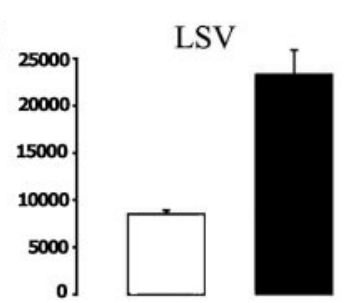

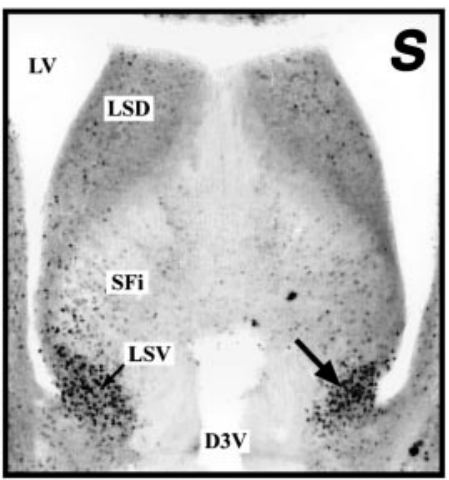

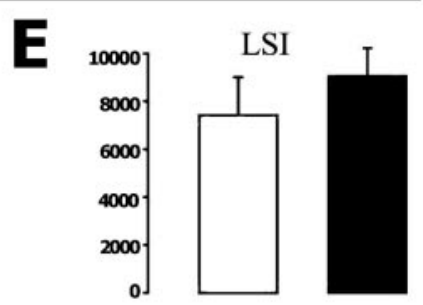

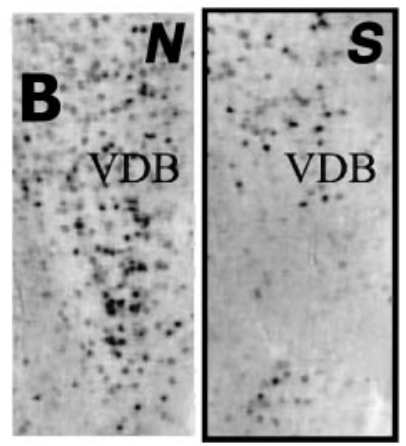

F

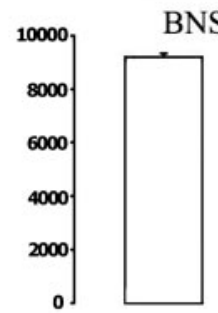

BNSTa
C

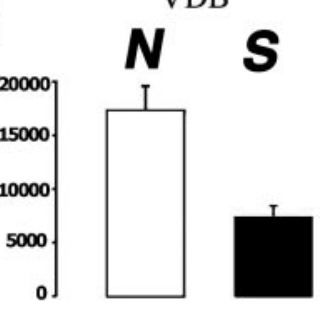

CST
G

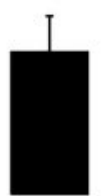

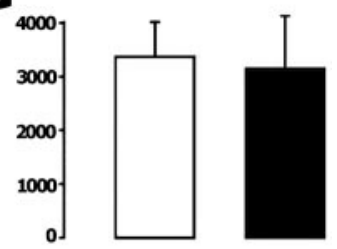
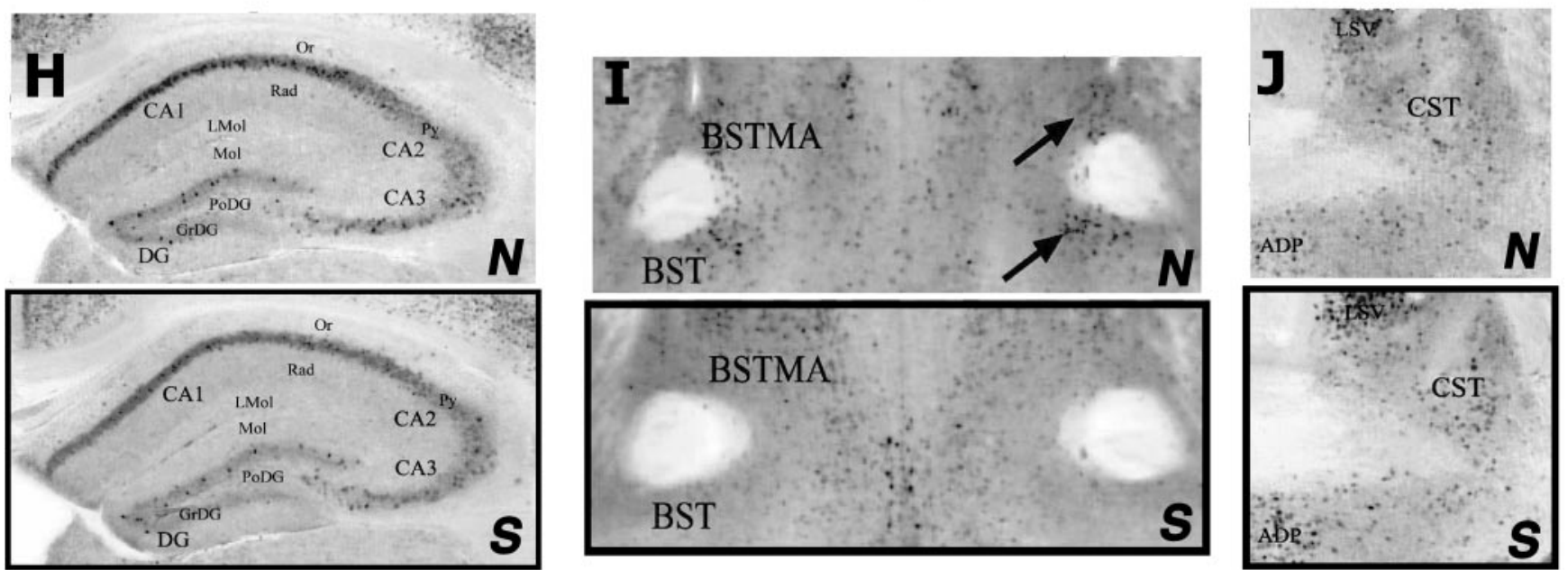

Figure 4. Pattern and density of staining in septo-hippocampal areas. Photomicrographs of the pattern of staining in the dorsal, intermediate, and ventral portions of the lateral septum (LSD, LSI, $\mathrm{LSV} ; A$ ), and the vertical limb of the diagonal band (VDB; $B$ ) are shown. Unframed images for each pair are from N mice; black-framed images are from $S$ mice. Stereological counting (cells per cubic millimeter \pm SEM) was performed in the VDB located between AP +1.2 and $+1.3 \mathrm{~mm}$ (volume, $0.041 \pm 0.004 \mathrm{~mm}^{3} ; C$, the LSV located between AP +0.1 and $-0.7 \mathrm{~mm}$ (volume, $0.120 \pm 0.004$ $\left.\mathrm{mm}^{3} ; D\right)$, and the LSI located between AP +0.5 and $+0.5 \mathrm{~mm}$ (volume, $0.255 \pm 0.018 \mathrm{~mm}^{3} ; E$ ). Student's $t$ tests indicated significant group differences for the LSV $(p<0.01)$ and the VDB $(p=$ 0.01), but not for the LSI. $H$, There were no differences between $N$ and S mice at the level of the dorsal hippocampus. Note the high density of cells in the pyramidal layer of CA1-CA3. There were contrasting effects in the BNSTa and CST. I, J, Photomicrographs show the distribution of cells in the BNSTa (l; BSTMA; arrows indicate the regions particularly stained in N mice) and the CST (J; surrounded by the LSV and the ADP). Stereological counting (cells per cubic millimeter \pm SEM) revealed a significant change in the BNSTa located between AP +0.5 and +0.4 mm (volume, $\left.0.071 \pm 0.002 \mathrm{~mm}^{3} ; p<0.05 ; F\right)$ but not in the CST located between AP +0.1 and $-0.2 \mathrm{~mm}$ (volume, $0.131 \pm 0.001 \mathrm{~mm}^{3} ; G$ ).

playing predominantly flight responses had twice the density of c-fos ${ }^{+}$cells in that area (Fig. $5 \mathrm{M}$ ). In the posterior striatum, including the amygdalostriatal transition area (Astr), cell density was not as high (Fig. $5 A, H$ ), but $\mathrm{N}$ mice again had significantly more cells than $\mathrm{S}$ mice (51\%; Fig. $5 \mathrm{~N}$ ). A particularly striking difference was observed in the shell of the nucleus accumbens (Acb), where $\mathrm{N}$ mice displayed a $147 \%$ higher density of c- $\mathrm{fos}^{+}$ cells than S mice (Fig. 5J,O).

\section{Cortical areas}

The only region of differential activity among posterior cortical areas was in the retrosplenial cortex (RS, also known as the posterior cingulate cortex; Fig. 6A). This change was particularly evident in the agranular layer of the RS (RSA) where cells were denser. There was a $43 \%$ increase in activity in the RSA (Fig. 6D), and there was also an apparent change in the granular layer of the RS (Fig. 6A). In contrast, there was no evidence of differential activity in the parietal association cortex, which is contiguous with the RS in the posterior cortex, or in the temporal association cortex (Fig. S7). In the motor cortex, which is adjacent to the RS at rostral levels, there was $58 \%$ more activity in $\mathrm{N}$ mice (as mentioned earlier; Fig. 2C,E). More ventrally, in the limb component of the somatosensory cortex, there were no apparent changes (Fig. S7F). As expected, staining was particularly strong in the auditory cortex, but again there was no indication of differential activity (Fig. S7G). Cell density also appeared equal between groups in regions of the temporal lobe, including the pyriform cortex, which had dense staining (Fig. S7D).

In area 2 of the anterior cingulate cortex, quantification revealed increased activity in $\mathrm{N}$ animals of even greater amplitude 

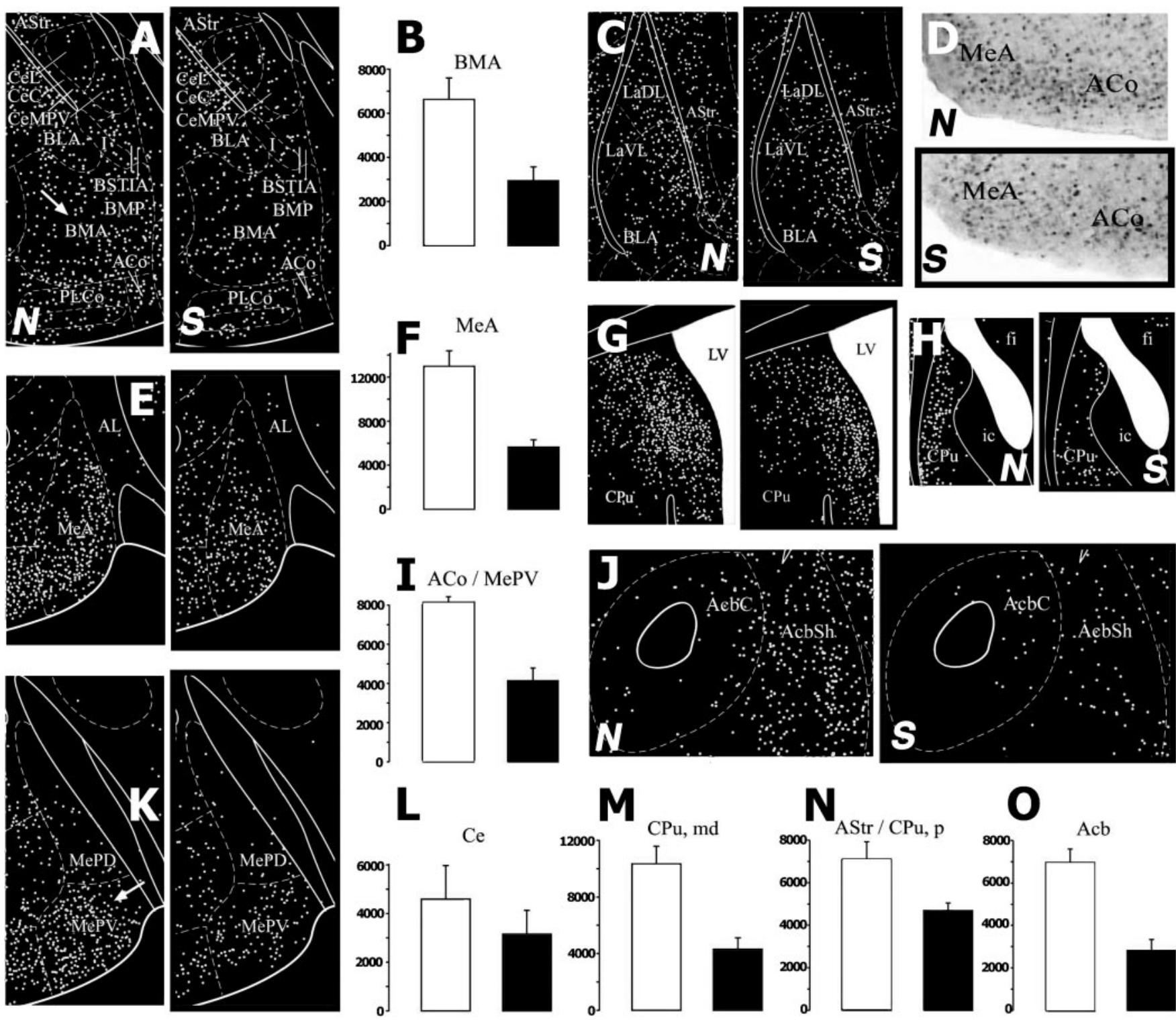

Figure 5. Data showing the greater density of staining in amygdalo-striatal areas of $\mathrm{N}$ versus $\mathrm{S}$ mice. Virtual sections show the distribution of cells in the basomedial and central amygdala (BMA, $(\mathrm{C} ; A)$, the lateral and the basolateral amygdala (La, BLA; () , the medial amygdala anterior (MeA; $E)$, and the ventral and dorsal portion of the medial amygdala posterior (MePV, MePD; $K)$. The microphotograph in D shows the dense cluster of cells at the boundary of the anterior cortical nucleus $(A C)$ and the MeA. Unframed images for each pair are from N mice; black-framed images are

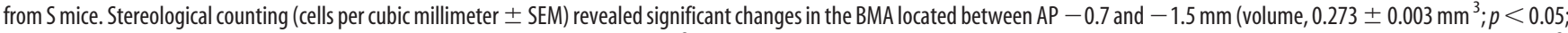
$B$ ), the MeA located between AP -0.6 and $-1.3 \mathrm{~mm}$ (volume, $0.129 \pm 0.002 \mathrm{~mm}^{3} ; p<0.01 ; F$ ), and the MePV and ACo located between AP -0.9 and $2.1 \mathrm{~mm}$ (volume, $0.424 \pm 0.009 \mathrm{~mm}$; $p<0.01 ; I)$. L, There was no significant change in Ce located between AP -0.8 and $-1.5 \mathrm{~mm}$ (volume, $0.259 \pm 0.006 \mathrm{~mm}^{3}$ ). The other virtual sections show the distribution of cells in the dorsomedial portion of the caudate putamen $(\mathrm{CPu} ; G)$, the posterior portion of the $\mathrm{CPu}(H)$, and the nucleus accumbens ( $\mathrm{Acb} ; \mathrm{J}$ [notice in $\mathrm{N}$ mice the higher density in the shell compared with the core of the accumbens ( $\mathrm{AcbSh}, \mathrm{Acb}$ )]. Stereological counting (cells per cubic millimeter \pm SEM) revealed significant changes in M) the mediodorsal (Pu located between AP +0.0 and $-1.2 \mathrm{~mm}$ (volume, $0.768 \pm 0.057 \mathrm{~mm}^{3} ; p=0.01 ; M$ ), the posterior (Pu and the Astr located between AP -1.0 and $-2.0 \mathrm{~mm}$ (volume, $0.693 \pm 0.039 \mathrm{~mm}^{3} ; p=0.05 ; N$ ), and the Acb located between $\mathrm{AP}+1.7$ and $+1.3 \mathrm{~mm}$ (volume, $0.645 \pm 0.019 \mathrm{~mm}^{3} ; p<0.01 ; 0$ ).

than that in the posterior cingulate cortex (Fig. $6 B, E$ ). The enhanced activity observed in the anterior cingulate cortex of $\mathrm{N}$ mice was contiguous with a similar change in the dorsal prefrontal cortex; there was a clear cluster of staining encompassing both area 1 of the anterior cingulate cortex $(\mathrm{Cg} 1)$ and the prelimbic cortex (Fig. $6 \mathrm{C}$ ). Both regions had more c-fos ${ }^{+}$cells in $\mathrm{N}$ than $\mathrm{S}$ mice, but a dorsoventral trend in cell distribution was often observed such that $\mathrm{N}$ mice displayed more activity in the Cg1 (51\%) than in the prelimbic cortex (30\%; Fig. $6 F, G)$. Other areas of the prefrontal cortex, such as the infralimbic, insular, and orbital cortex, did not show any signs of differential activity (Fig. S5).

\section{Discussion}

We have defined a novel behavioral paradigm in which defensive behaviors are reliably elicited from mice by an aversive unimodal stimulus on first presentation. Naive animals in their home cage predominantly display flight responses to a patterned ultrasonic stimulus, whereas a novel environment or previous foot shock sensitization enhances freezing and suppresses flight. Flight and freezing behaviors are negatively correlated, suggesting the existence of opponent neural circuits mediating these motor responses. Our behavioral data suggest, moreover, that the balance between these behaviors is shifted from flight to freezing by 

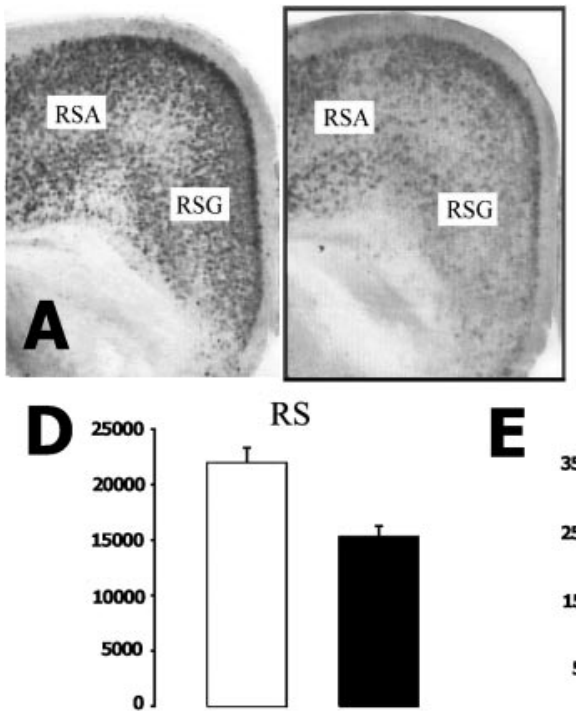

RS

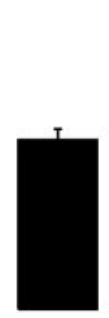

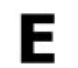
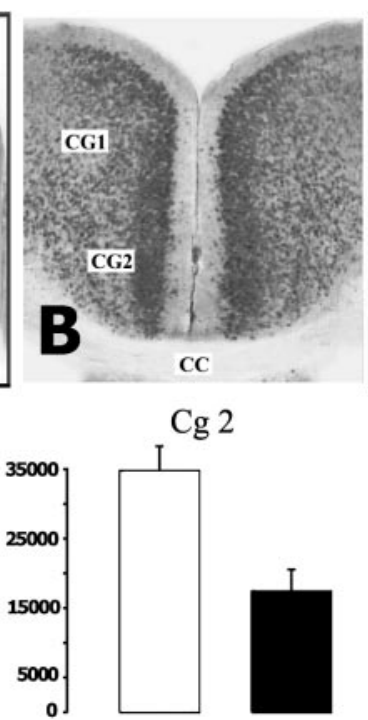

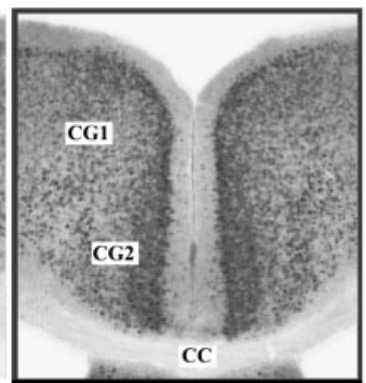

$\boldsymbol{F}$

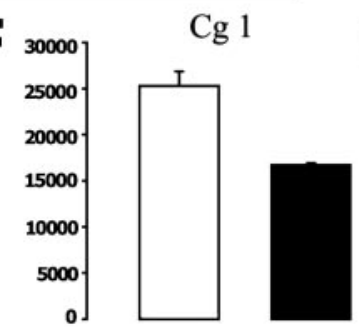

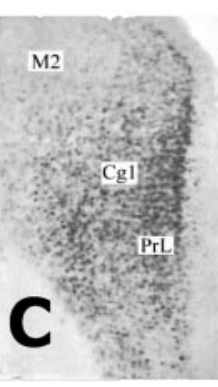

$\mathbf{G}$

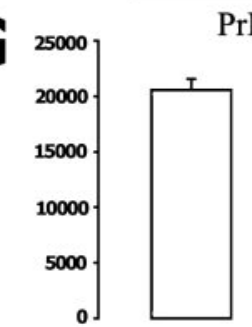

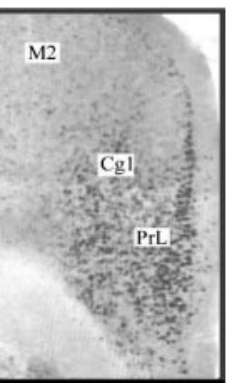

$\operatorname{PrL}$

Figure 6. Evidence for greater activity in cingulate and dorsal prefrontal cortices of $\mathrm{N}$ versus $\mathrm{S}$ mice. Photomicrographs show the differential activity in $\mathrm{A})$ the granular and agranular layers of the retrosplenial cortex (RSG, $\mathrm{RSA} ; A)$, areas 1 and 2 of the anterior cingulate cortex ( $\mathrm{Cg} 1, \mathrm{Cg} 2 ; B)$, and the prelimbic cortex and the most rostral part of the anterior cingulate cortex (PrL, $C \mathrm{~g} 1 ; \mathrm{C}[\mathrm{no}$ change in the adjacent nose component of the motor cortex (M2)]. Unframed images for each pair are from N mice; black-framed images are from S mice. Stereological counting (cells per cubic millimeter \pm SEM) shows an enhancement in cortical activity in N versus $S$ mice. Student's t tests indicated significant effects in the granular retrosplenial cortex located between AP -1.8 and $2.7 \mathrm{~mm}$ (volume, $\left.0.280 \pm 0.011 \mathrm{~mm}^{3} ; p<0.05 ; D\right)$, Cg2 located between AP +0.1 and $-0.7 \mathrm{~mm}$ (volume, $0.168 \pm 0.005 \mathrm{~mm}^{3} ; p<0.05 ; E$ ), Cg1 located between AP +2.1 and $+1.6 \mathrm{~mm}$ (volume, $0.260 \pm 0.008$ $\left.\mathrm{mm}^{3} ; p<0.01 ; F\right)$, and PrL located between AP +2.1 and $+1.6 \mathrm{~mm}$ (volume, $0.277 \pm 0.006 \mathrm{~mm}^{3} ; p<0.05 ; G$ ).

increased stress or anxiety. As a first step toward elucidating the circuitry mediating this competition, we have compared the global patterns of c-fos activation in mice displaying predominantly flight $(\mathrm{N})$ or freezing $(\mathrm{S})$. An analysis of several brain areas has identified subsets of regions preferentially activated in $\mathrm{N}$ or $\mathrm{S}$ animals (Fig. 7).

\section{Ultrasound-induced defense and its modulation}

The design of this paradigm allowed both flight and freezing behaviors to be independently performed at maximal levels during the testing session. In fact, some mice displayed flight during the ON period and then freezing immediately afterward during the OFF period, followed again by flight, and so on (Fig. 1C). However, when assessed using a large number of animals, a negative correlation between flight and freezing behaviors was observed. This negative correlation is consistent with ethological observations of flight and freezing in responses to predators (Blanchard et al., 1989, 2001). We also observed an acoustic startle response to the USS in some mice. However, in contrast to flight, the acoustic startle defense reflex, which was most often observed in $\mathrm{S}$ mice or mice placed in a new cage, is positively correlated with freezing behavior (Leaton and Borszcz, 1985) and facilitated by previous foot shock sensitization (Gewirtz et al., 1998). The fact that freezing is, like startle, enhanced by foot shock sensitization suggests that these two behaviors are modulated by aversive events in a similar manner, contrary to freezing and flight, which appear as opponent defense behaviors.

Why do foot shock sensitization and a novel environment inhibit flight and promote freezing? Our feeding suppression data, which are consistent with previous studies (Bodnoff et al., 1988; Steenbergen et al., 1990), and our anxiolytic drug administration data suggest that anxiety is an important factor. One simple interpretation of our data, therefore, is that freezing requires a higher threshold level of anticipatory fear or anxiety to be elicited by the USS. This would be consistent with the view of Gray (1971) that “"prepared' (or) 'innate stimuli for fear' . . . require some additional source of emotional disturbance before ... they elicit ... a full-blooded fear reaction." In this view, the USS is a "prepared" (innately fearful) stimulus for the expression of freezing and becomes a releaser of this behavior in the presence of elevated anticipatory fear or anxiety. The fact that flight is, conversely, suppressed under the same conditions also fits with the idea that anticipatory anxiety suppresses panic-like behaviors, such as flight reactions (Deakin et al., 1992). Nevertheless, it should be noted that flight in response to a threat can sometimes reflect a higher state of acute fear than does freezing, because it displaces freezing when danger becomes more imminent or proximal (Blanchard et al., 1989).

The fact that foot shocks can cause the USS to elicit a freezing response $24 \mathrm{hr}$ later suggests that this phenomenon reflects sensitization and not classical conditioning (Gray, 1971). An alternative interpretation is that the freezing that occurs in sensitized mice is a conditioned response, which reflects previous associative learning between the foot shocks and the context in which it was delivered and results from a generalization of this contextual fear conditioning the next day (Fanselow, 1980). However, this interpretation seems very unlikely, because there were no common features between the training and the testing contexts. Furthermore, it does not account for the fact that a similar shift from flight to freezing is also caused simply by placing the animal in an unfamiliar cage, where mnemonic effects are excluded.

It is also worth mentioning that the present sensitization model resembles the learned helplessness $(\mathrm{LH})$ model in which mice exposed to inescapable foot shocks typically show performance deficits when later given the opportunity to learn to escape the foot shocks (i.e., in a shuttle box). However, the foot shock protocol used here is milder than that required to induce $\mathrm{LH}$. More importantly, what is measured in LH is not flight per se but an operant response, the ability of the animal to learn to escape a 


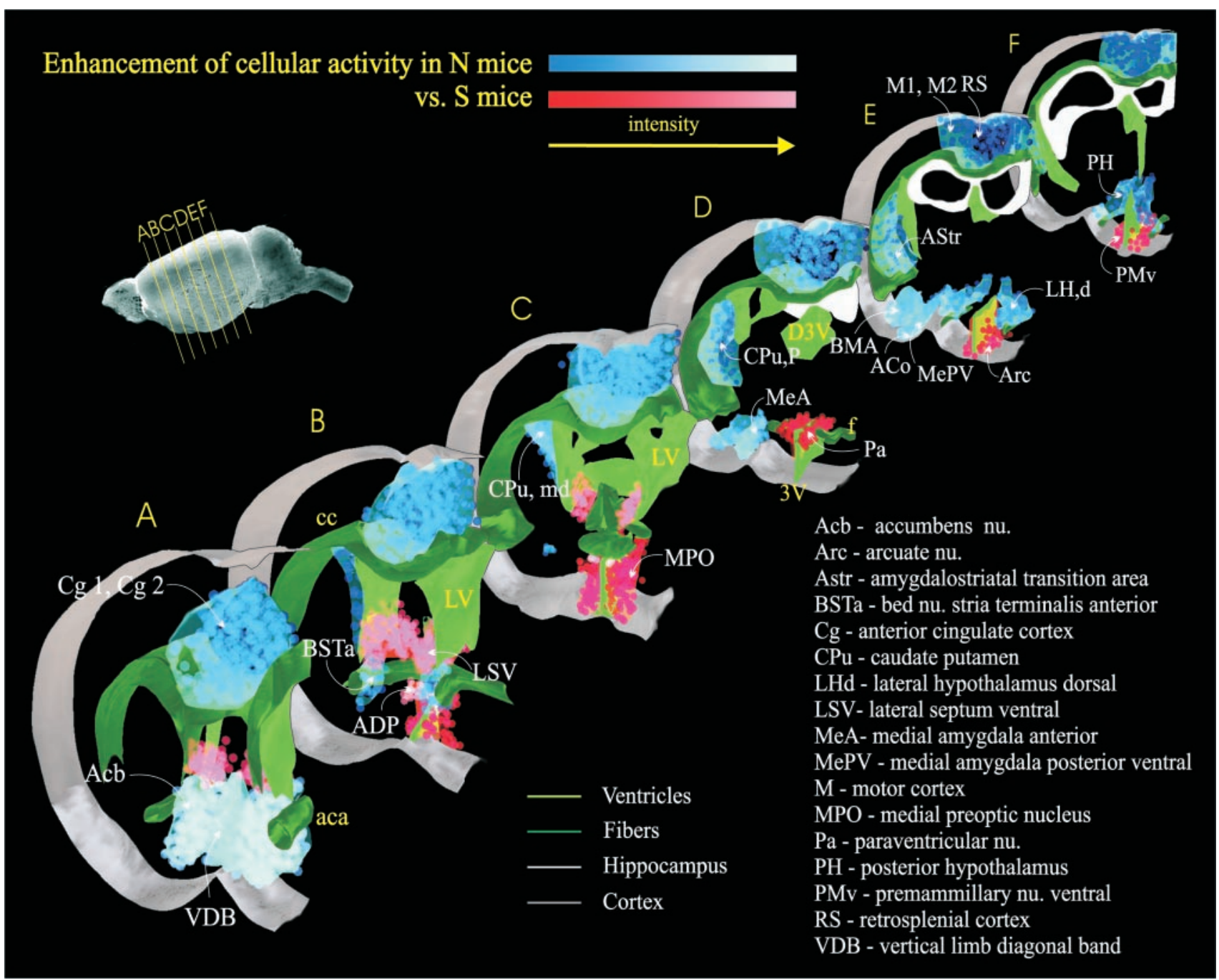

Figure 7. Cross-sectional diagram of the forebrain summarizing the results of the present study. Areas of preferential activity in N and $\mathrm{S}$ mice are indicated in blue and red, respectively, with the color brightness representing the approximate intensity of the differences. Areas showing strong but equal c-fos expression in both N and S mice are omitted for clarity (see on-line Table 1, available at www.jneurosci.org). See Results for details. An animated three-dimensional version of this summary diagram can be seen in on-line Appendix B.

shock. By contrast, the undirected flight assessed here appears to be an innate behavior. Nevertheless, the suppression of flight and enhancement of freezing we observe in S mice may involve some processes in common with LH.

\section{Overview of the neural correlates of USS-induced flight versus freezing}

Efforts to elucidate the neuroanatomy of fear-mediated motor responses have led to the concept of a hierarchy of neural systems mediating defensive behaviors such as flight and freezing (LeDoux, 1995; Gray and McNaughton, 2000). From the lowest to the highest levels of this hierarchy are the midbrain periaqueductal gray, the hypothalamus, the amygdala, the septo-hippocampal areas, and the cingulate cortex. All of these systems receive sensory information about fearful stimuli through various routes. Components of this hierarchy are believed to regulate progressively more evolved forms of defense, such that phylogenetically older neural systems generate "quick and dirty" strategies dealing with imminent danger, whereas more evolved brain areas produce slower but more sophisticated reactions (Graeff, 1994). These multiple systems are known to interact with each other, but the neural mechanisms that mediate switches between alternative motor defensive behaviors remain to be elucidated. The goal of the present study was to observe whether there was any change in brain activity correlating with different defense behaviors elicited by the same stimulus. Our results identify several areas of the forebrain that exhibit differences in c-fos expression during flight versus freezing behaviors. Although there are no preexisting theoretical models to provide a framework for the interpretation of these data, an examination of the literature on the function and connectivity of these areas suggests a heuristic circuit controlling the switch between these behaviors, which makes testable predictions. (See also on-line Appendix C, available at www.jneurosci.org).

Two main features stand out in our analysis of c-fos activation patterns in the forebrains of $\mathrm{N}$ and $\mathrm{S}$ mice (summarized in Fig. 7). The first is the preferential activation in $\mathrm{N}$ mice of a corticoamygdalo-striatal processing stream mediating active motor defenses (Fig. 7, blue). It is not surprising that these areas are less active in $\mathrm{S}$ mice, because these animals are less motile. The second and less expected feature is a pattern of reciprocal activation in septal and hypothalamic areas of $\mathrm{N}$ and $\mathrm{S}$ mice. In $\mathrm{N}$ mice, there 

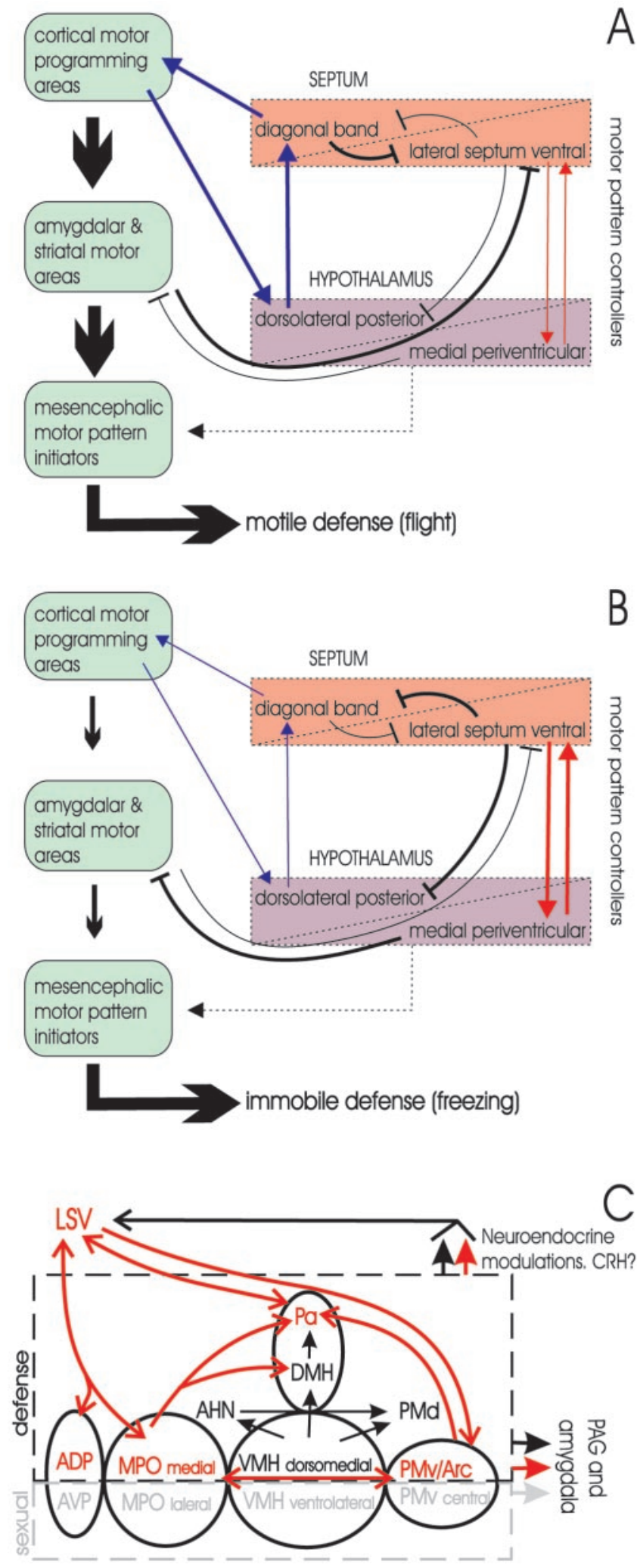

Figure 8. Hypothetical circuit illustrating the interactions between brain areas leading to either A) motile defense $(A)$ or immobile defense $(B)$. $C$, Septal and hypothalamic nuclei believed to be involved in behavioral inhibition in the context of other known functional columns. $A$, A stream of activity in motor programming cortical areas (e.g., $\mathrm{Cg}, \mathrm{RS}$, and $\mathrm{PrL}$ ) and amygdalo-striatal motor regions would trigger motile defense via the mesencephalic motor pattern initiators (e.g., PAG, CnF, and PPTg). A putative positive feedback loop (blue arrows) from the motor programming cortical areas to the dorsolateral posterior hypothalamic zone $(\mathrm{PH}, \mathrm{LH})$ may maintain activity in the septal VDB, which in turn could limit behavioral inhibition is preferential activity in the VDB of the septum and in the dorsolateral posterior zone of the hypothalamus (which projects to the VDB; Vertes et al., 1995) (Fig. 8A). The VDB sends ascending excitatory projections to the retrosplenial cortex (Gonzalo-Ruiz and Morte, 2000) and associated motor programming areas, which are also more active in $\mathrm{N}$ mice and which project in turn back to the dorsolateral posterior hypothalamus (Floyd et al., 2001) (Figs. 8A, blue arrows, S8). This apparent positivefeedback loop could potentially reinforce active motor behavior in $\mathrm{N}$ mice.

By contrast, in S mice there is enhanced activity in the LSV and in the medial periventricular zone of the hypothalamus (Fig. $8 B$, red arrows). These regions are heavily interconnected (Sakanaka et al., 1988; Jakab and Leranth, 1995; Risold and Swanson, 1997) and may also form a self-reinforcing circuit (Fig. 8C). Outputs from the lateral septum, medial periventricular hypothalamus, or both could, in principle, inhibit the cortico-amygdalo-striatal motor processing stream at several levels, including the VDB and the shell of the Acb in the striatum (Simerly and Swanson, 1988; Staiger and Nurnberger, 1991) (Fig. 8B, blunt arrows). Importantly, the VDB in turn is thought to send inhibitory projections back to the LSV (Staiger and Nurnberger, 1989; Jakab and Leranth, 1995; Kiss et al., 1997) (Fig. 8A, blunt arrow). The reciprocal inhibition between the VDB and LSV could, therefore, comprise part of a bistable switch circuit that controls flight versus freezing behaviors. Additional evidence in support of this interpretation from previous connectional, lesioning, and stimulation studies is discussed in more detail in on-line Appendix C.

As mentioned earlier, much more is known about the circuits for learned (conditioned) fear compared with those for innate fear, because of difficulties in controlling the quality and quantity of stimuli used to induce the latter. In principle, the circuits for innate fear could be identical, partially overlapping, or completely independent from those for learned fear. Some evidence suggests that innately fearful or anxiogenic stimuli may be processed by different circuits than those for conditioned fearful stimuli (Walker and Davis, 1997; Wallace and Rosen, 2001; Fendt et al., 2003). With the present paradigm, the ability to reliably elicit defensive responses from laboratory mice by a parametrically well defined auditory stimulus on first presentation now provides an opportunity to make more direct comparisons between the circuits underlying innate and conditioned fear reactions to auditory cues.

Finally, the present studies define a novel experimental paradigm for understanding the neural basis of contextual and experiential influences on defensive reactions to an innately aversive stimulus. Our results suggest that flight and freezing can compete

through is inhibitory projections to the LSV (blunt arrows). The LSV could also be inhibited via projections from the medial amygdala. $B$, The LSV would inhibit flight by suppressing activity in the VDB. This inhibition could be reinforced by positive feedback interactions with hypothalamic nuclei of the medial periventricular zone (red arrows; e.g. ADP, MPO, and Pa). This hypothalamic zone could also independently inhibit areas subserving motile defense through direct and indirect projections (blunt arrows). The lateral septum, through descending GABAergic projections, could also decrease the activity of the dorsolateral posterior hypothalamic zone. C, Regions of the medial periventricular zone of the hypothalamus and the LSV are extensively interconnected (red represents pathways predominantly active in S mice). Black represents areas involved in defense and that have equal but moderate to intense c-fos activity in both groups. Light gray represents adjacent hypothalamic areas, involved in sexual behaviors, which displayed low activity to the aversive ultrasound. All these hypothalamic zones control behaviors through their projections to the PAG or the amygdala. The LSV, via the hypothalamus, is also likely to modulate the release of stress factors such as CRH, which induce c-fos activity in the LSV. 
for the expression of fear depending on levels of anxiety present before the presentation of this stimulus. These observations in turn raise the question of where and how anxiety modifies defensive behavioral outputs to an aversive stimulus. The c-fos mapping data provide a heuristic circuit for the regulation of these competing behaviors by anxiety or stress, which may now be tested by systematic functional perturbation experiments. This system may also provide a useful model for understanding the neural substrates of human fear disorders, such as panic and anxiety, as well as for drugs used to treat them.

\section{References}

Alheid GF, Olmos JS, Beltramino CA (1995) Amygdala and extended amygdala. In: The rat nervous system (Paxinos G, ed), pp 495-578. San Diego: Academic.

Anokhin KV, Mileusnic R, Shamakina IY, Rose SP (1991) Effects of early experience on c-fos gene expression in the chick forebrain. Brain Res 544:101-107.

Bandler R, Keay KA, Floyd N, Price J (2000) Central circuits mediating patterned autonomic activity during active vs. passive emotional coping. Brain Res Bull 53:95-104.

Beckett SR, Aspley S, Graham M, Marsden CA (1996) Pharmacological manipulation of ultrasound induced defence behaviour in the rat. Psychopharmacology 127:384-390.

Blanchard DC, Griebel G, Blanchard RJ (2001) Mouse defensive behaviors: pharmacological and behavioral assays for anxiety and panic. Neurosci Biobehav Rev 25:205-218.

Blanchard RJ, Blanchard DC, Hori K (1989) An ethoexperimental approach to the study of defense. In: Ethoexperimental approaches to the study of behavior (Blanchard RJ, ed), pp 114-136. Dordrecht, The Netherlands: Kluwer.

Blanchard RJ, Agullana R, McGee L, Weiss S, Blanchard DC (1992) Sex differences in the incidence and sonographic characteristics of antipredator ultrasonic cries in the laboratory rat (Rattus norvegicus). J Comp Psychol 106:270-277.

Bodnoff SR, Suranyi-Cadotte B, Aitken DH, Quirion R, Meaney MJ (1988) The effects of chronic antidepressant treatment in an animal model of anxiety. Psychopharmacology 95:298-302.

Canteras NS (2002) The medial hypothalamic defensive system: hodological organization and functional implications. Pharmacol Biochem Behav 71:481-491.

Canteras NS, Chiavegatto S, Valle LE, Swanson LW (1997) Severe reduction of rat defensive behavior to a predator by discrete hypothalamic chemical lesions. Brain Res Bull 44:297-305.

Castro-Alamancos MA, Borrell J, Garcia-Segura LM (1992) Performance in an escape task induces fos-like immunoreactivity in a specific area of the motor cortex of the rat. Neuroscience 49:157-162.

Cazala P, Schmitt P (1987) Dorso-ventral variation in the attenuating effect of lateral hypothalamic stimulation on the switch-off response elicited from the mesencephalic central gray area. Physiol Behav 40:625-629.

Cuomo V, Cagiano R, Desalvia MA, Mazzoccoli M, Persichella M, Renna G (1992) Ultrasonic vocalization as an indicator of emotional state during active-avoidance learning in rats. Life Sci 50:1049-1055.

Deakin JF, Graeff FG, Guimaraes F (1992) 5-HT receptor subtypes and the modulation of aversion. In: Central serotonin receptors and psychotropic drugs (Marsden C, Heal DJ, eds), pp 147-174. London: Blackwell.

Dielenberg RA, Hunt GE, McGregor IS (2001) "When a rat smells a cat": the distribution of Fos immunoreactivity in rat brain following exposure to a predatory odor. Neuroscience 104:1085-1097.

Ehret G, Fischer R (1991) Neuronal activity and tonotopy in the auditory system visualized by c-fos gene expression. Brain Res 567:350-354.

Fanselow MS (1980) Conditional and unconditional components of postshock freezing. Pavlov J Biol Sci 15:177-182.

Fendt M, Endres T, Apfelbach R (2003) Temporary inactivation of the bed nucleus of the stria terminalis but not of the amygdala blocks freezing induced by trimethylthiazoline, a component of fox feces. J Neurosci 23:23-28.

Finkbeiner S, Greenberg ME (1998) Ca2+ channel-regulated neuronal gene expression. J Neurobiol 37:171-189.
Floyd NS, Price JL, Ferry AT, Keay KA, Bandler R (2001) Orbitomedial prefrontal cortical projections to hypothalamus in the rat. J Comp Neurol 432:307-328

Geuna S (2000) Appreciating the difference between design-based and model-based sampling strategies in quantitative morphology of the nervous system. J Comp Neurol 427:333-339.

Gewirtz JC, McNish KA, Davis M (1998) Lesions of the bed nucleus of the stria terminalis block sensitization of the acoustic startle reflex produced by repeated stress, but not fear-potentiated startle. Prog Neuropsychopharmacol Biol Psychiatry 22:625-648.

Gonzalo-Ruiz A, Morte L (2000) Localization of amino acids, neuropeptides and cholinergic markers in neurons of the septum-diagonal band complex projecting to the retrosplenial granular cortex of the rat. Brain Res Bull 52:499-510.

Graeff FG (1990) Brain defense systems and anxiety. In: Handbook of anxiety: the neurobiology of anxiety (Burrows GD, Roth M, Noyes R, eds), pp 307-354. Amsterdam: Elsevier.

Graeff FG (1994) Neuroanatomy and neurotransmitter regulation of defensive behaviors and related emotions in mammals. Braz J Med Biol Res 27:811-829.

Gray JA (1971) The psychology of fear and stress. Cambridge: Cambridge UP.

Gray JA, McNaughton N (2000) The neuropsychology of anxiety. Oxford: Oxford Medical.

Greenberg ME, Ziff EB (1984) Stimulation of 3T3 cells induces transcription of the c-fos proto-oncogene. Nature 311:433-438.

Gross C, Santarelli L, Brunner D, Zhuang X, Hen R (2000) Altered fear circuits in 5-HT(1A) receptor KO mice. Biol Psychiatry 48:1157-1163.

Helmreich DL, Cullinan WE, Watson SJ (1996) The effect of adrenalectomy on stress-induced c-fos mRNA expression in the rat brain. Brain Res 706:137-144.

Herdegen T, Leah JD (1998) Inducible and constitutive transcription factors in the mammalian nervous system: control of gene expression by Jun, Fos and Krox, and CREB/ATF proteins. Brain Res Rev 28:370-490.

Howard CV, Rose SP (1998) Unbiased stereology: three-dimensional measurement in microscopy. New York: BIOS Scientific.

Jakab RL, Leranth C (1995) Septum. In: The rat nervous system (Paxinos G, ed), pp 405-442. San Diego: Academic.

Kiss J, Borhegyi Z, Csaky A, Szeiffert G, Leranth C (1997) Parvalbumin containing cells of the angular portion of the vertical limb terminate on calbindin-immunoreactive neurons located at the border between the lateral and medial septum of the rat. Exp Brain Res 113:48-56.

Leaton RN, Borszcz GS (1985) Potentiated startle: its relation to freezing and shock intensity in rats. J Exp Psychol 11:421-428.

LeDoux JE (1995) Emotion: clues from the brain. Annu Rev Psychol 46:209-235.

Li CX, Waters RS (1991) Organization of the mouse motor cortex studied by retrograde tracing and intracortical microstimulation (ICMS) mapping. Can J Neurol Sci 18:28-38.

Maren S, Fanselow MS (1996) The amygdala and fear conditioning: has the nut been cracked? Neuron 16:237-240.

Mayhew TM, Gundersen HJ (1996) If you assume, you can make an ass out of $u$ and me: a decade of the dissector for stereological counting of particles in 3D space. J Anat 188:1-15.

McGeorge AJ, Faull RL (1989) The organization of the projection from the cerebral cortex to the striatum in the rat. Neuroscience 29:503-537.

Paxinos G, Franklin KBJ (2001) The mouse brain in stereotaxic coordinates. Hong Kong: Academic.

Pfaus JG, Kleopoulos SP, Mobbs CV, Gibbs RB, Pfaff DW (1993) Sexual stimulation activates c-fos within estrogen-concentrating regions of the female rat forebrain. Brain Res 624:253-267.

Risold PY, Swanson LW (1997) Connections of the rat lateral septal complex. Brain Res Rev 24:115-195.

Ryan AF, Furlow Z, Woolf NK, Keithley EM (1988) The spatial representation of frequency in the rat dorsal cochlear nucleus and inferior colliculus. Hear Res 36:181-189.

Sakanaka M, Magari S, Shibasaki T, Lederis K (1988) Corticotropin releasing ing factor-containing afferents to the lateral septum of the rat brain. J Comp Neurol 270:404-407.

Staiger JF, Nurnberger F (1989) Pattern of afferents to the lateral septum in the guinea pig. Cell Tissue Res 257:471-490.

Staiger JF, Nurnberger F (1991) The efferent connections of the lateral sep- 
tal nucleus in the guinea pig: intrinsic connectivity of the septum and projections to other telencephalic areas. Cell Tissue Res 264:415-426.

Steenbergen HL, Heinsbroek RP, Van Hest A, van de Poll NE (1990) Sexdependent effects of inescapable shock administration on shuttleboxescape performance and elevated plus-maze behavior. Physiol Behav 48:571-576.

Simerly RB, Swanson LW (1988) Projections of the medial preoptic nucleus: a Phaseolus vulgaris leucoagglutinin anterograde tract-tracing study in the rat. J Comp Neurol 270:209-242.

Vertes RP, Crane AM, Colom LV, Bland BH (1995) Ascending projections of the posterior nucleus of the hypothalamus: PHA-L analysis in the rat. J Comp Neurol 359:90-116.
Walker DL, Davis M (1997) Double dissociation between the involvement of the bed nucleus of the stria terminalis and the central nucleus of the amygdala in startle increases produced by conditioned versus unconditioned fear. J Neurosci 17:9375-9383.

Wallace KJ, Rosen JB (2001) Neurotoxic lesions of the lateral nucleus of the amygdala decrease conditioned fear but not unconditioned fear of a predator odor: comparison with electrolytic lesions. J Neurosci 21:3619-3627.

Yokosuka M, Matsuoka M, Ohtani-Kaneko R, Iigo M, Hara M, Hirata K, Ichikawa M (1999) Female-soiled bedding induced fos immunoreactivity in the ventral part of the premammillary nucleus (PMv) of the male mouse. Physiol Behav 68:257-261. 